\title{
Benthic foraminifera from an equatorial Pacific seamount during greenhouse climate
}

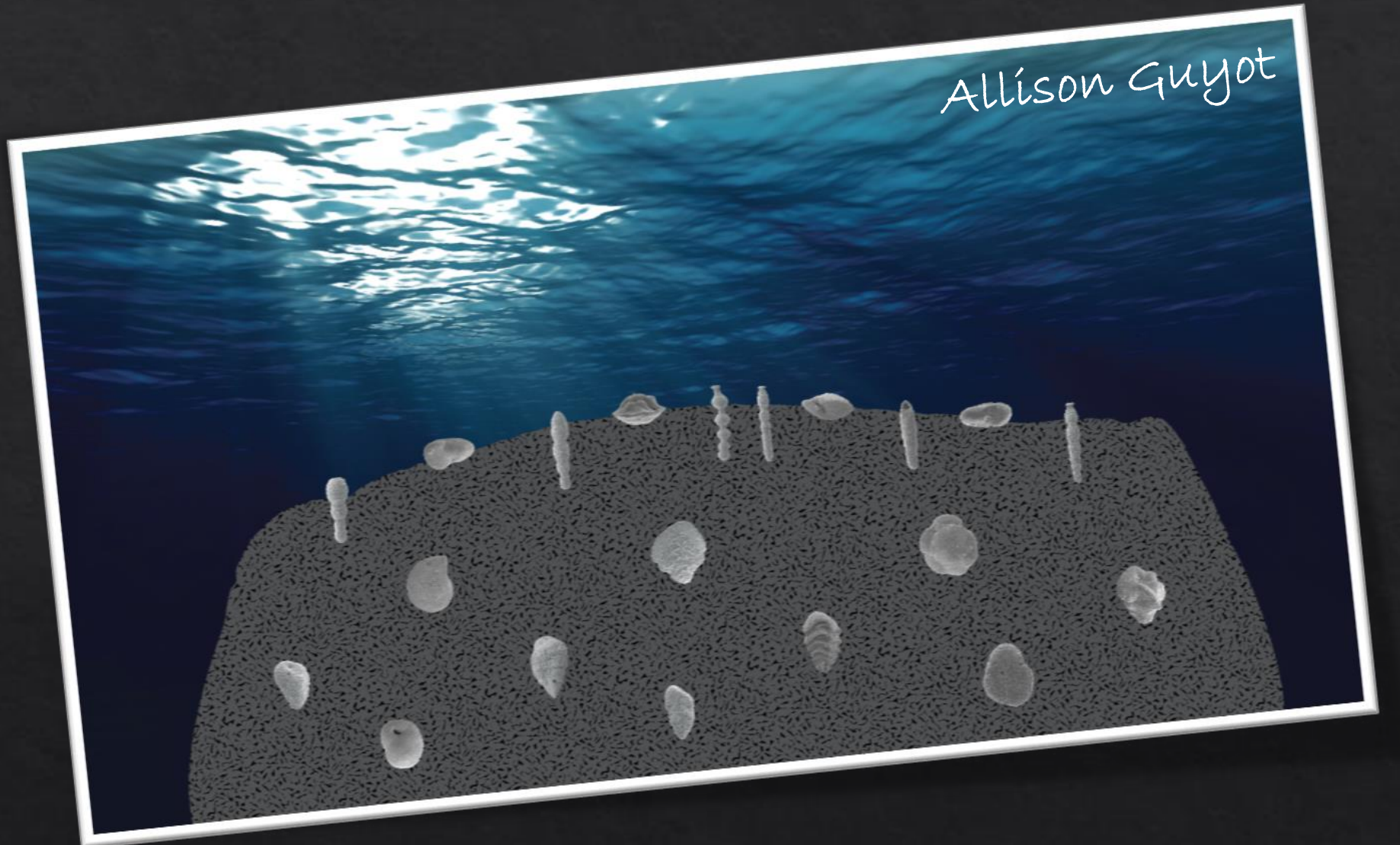

Gabriela J. Arreguín-Rodríguez, Laia Alegret \& Ellen Thomas 


\section{Main points:}

- Composition of benthic foraminiferal assemblages on a Pacific seamount, an unusual setting.

- Which factors influence them:

- Primary productivity

- Transfer to seafloor $\}$ Food

- Current activity

- Response of the assemblages to warming events of different magnitude superimposed on a greenhouse climate. 


\section{Why study benthic foraminifera?}

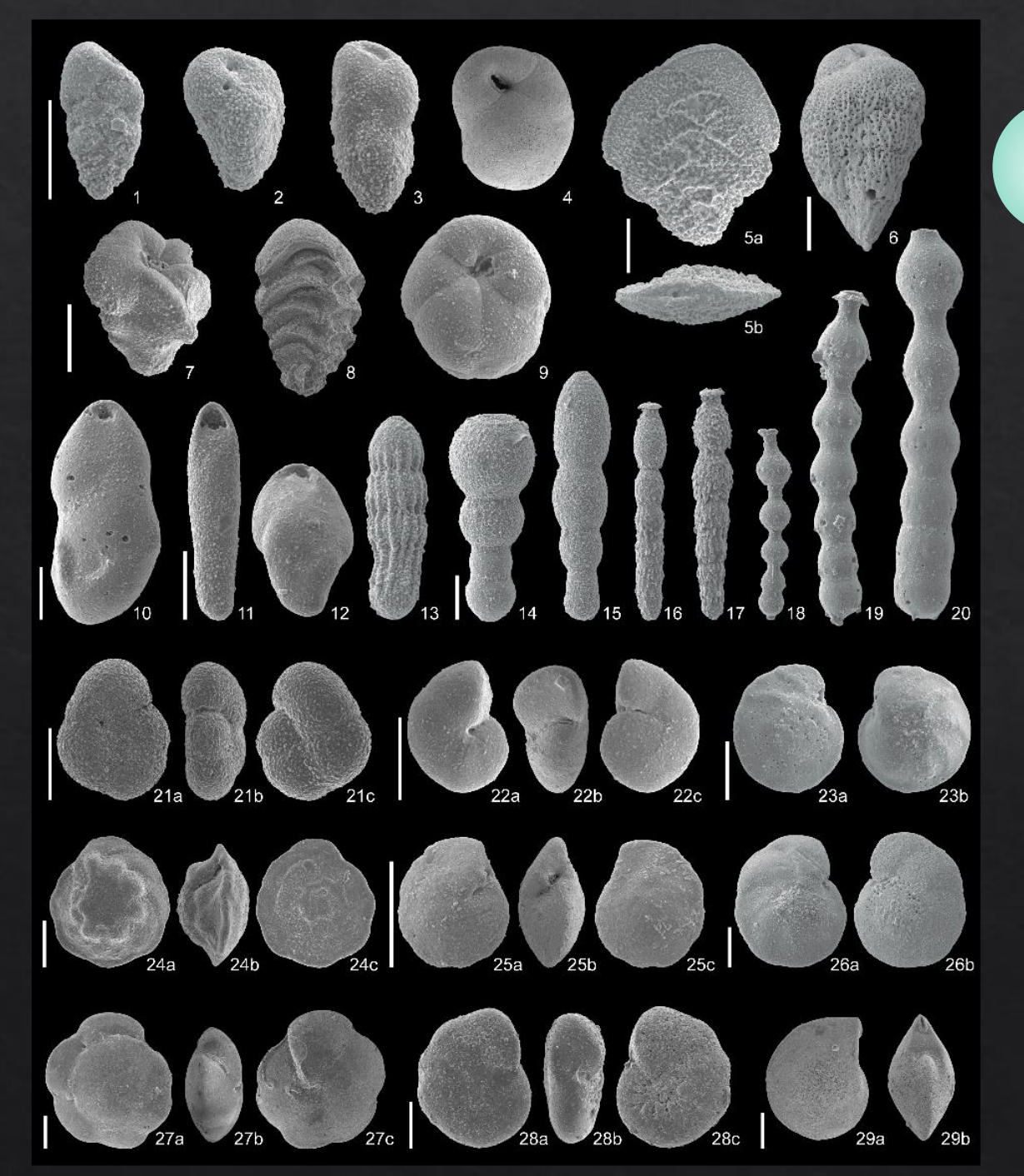

\section{1}

Eukaryote, heterotroph, unicellular organisms.

Some make multi-chambered $\mathrm{CaCO}_{3}$ or agglutinated-sediment shells.

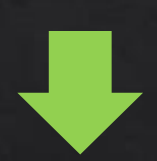

$\mathrm{CaCO}_{3}$ used for trace elements/isotope studies to reconstruct environmental parameters

\section{2}

Biota most commonly represented in the microfossil record from the deep sea floor.

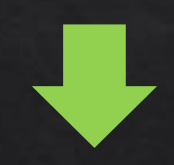

Deep sea ecosystems are the largest habitat on Earth 


\section{Greenhouse climate and hyperthermal events}

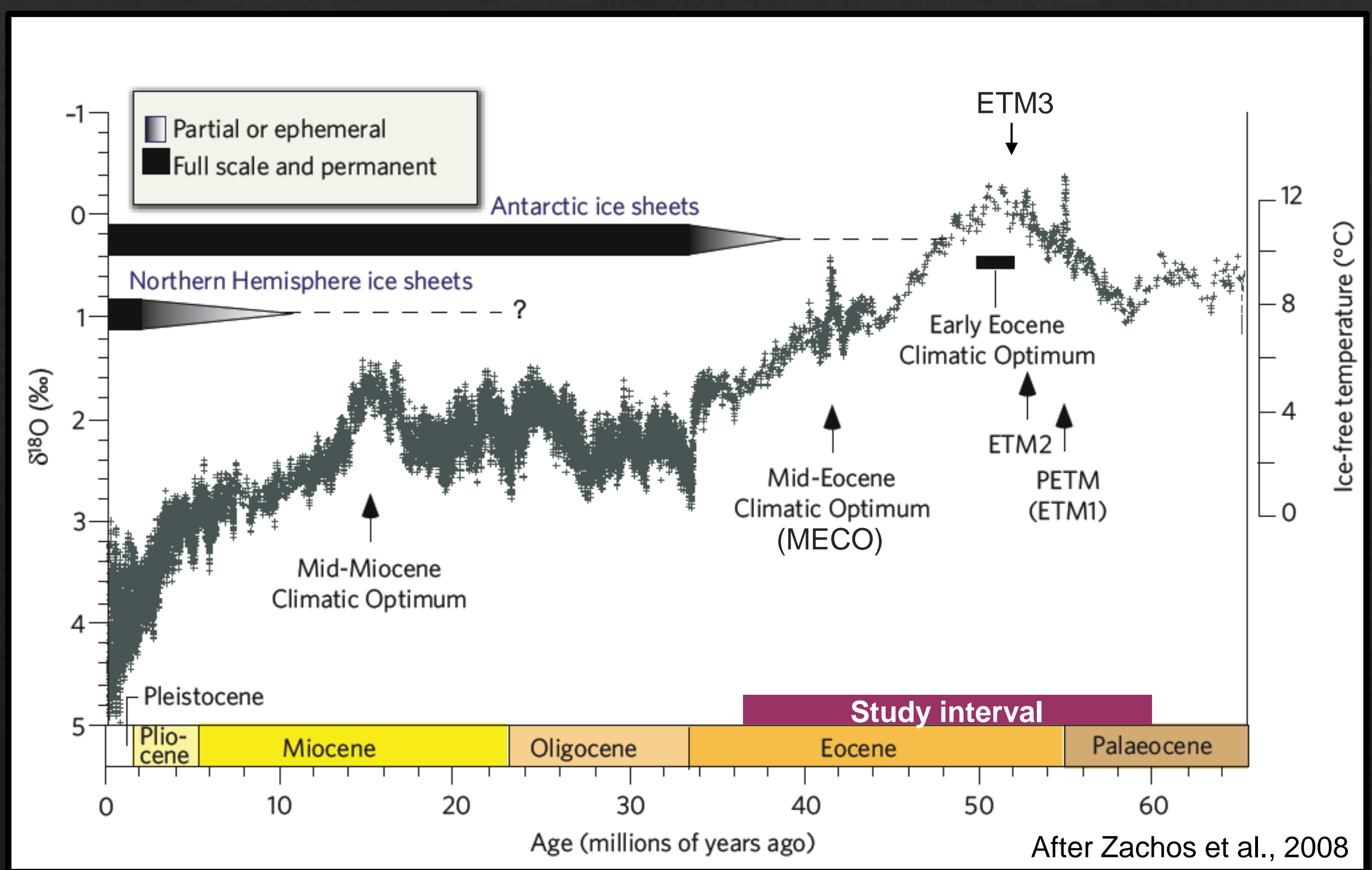

\section{Greenhouse}

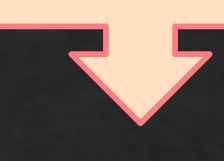

Early Paleogene characterized by long-term global warming trend 


\section{Greenhouse climate and hyperthermal events}

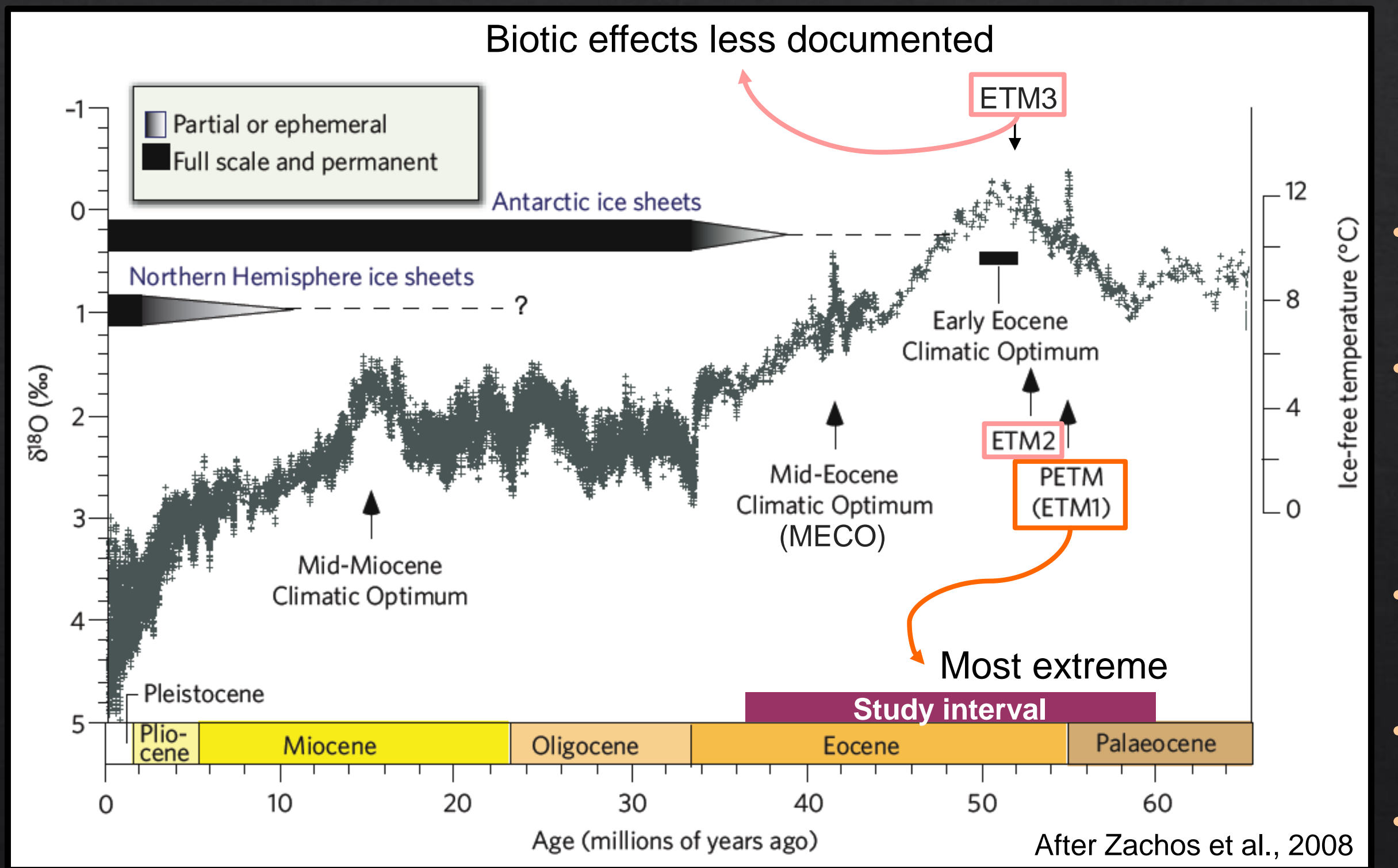

\section{Hyperthermals}

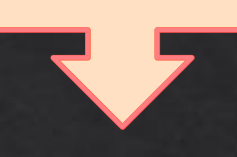

Oxygen isotope excursions:

$\longleftrightarrow$ warming

- Negative carbon isotope excursions (CIEs):

$\llcorner$ emission of isotopically light carbon

- Dissolution of $\mathrm{CaCO}_{3}$ :

$\longrightarrow$ ocean acidification

- Continental weathering

- Biotic perturbations 


\section{Greenhouse climate and hyperthermal events}
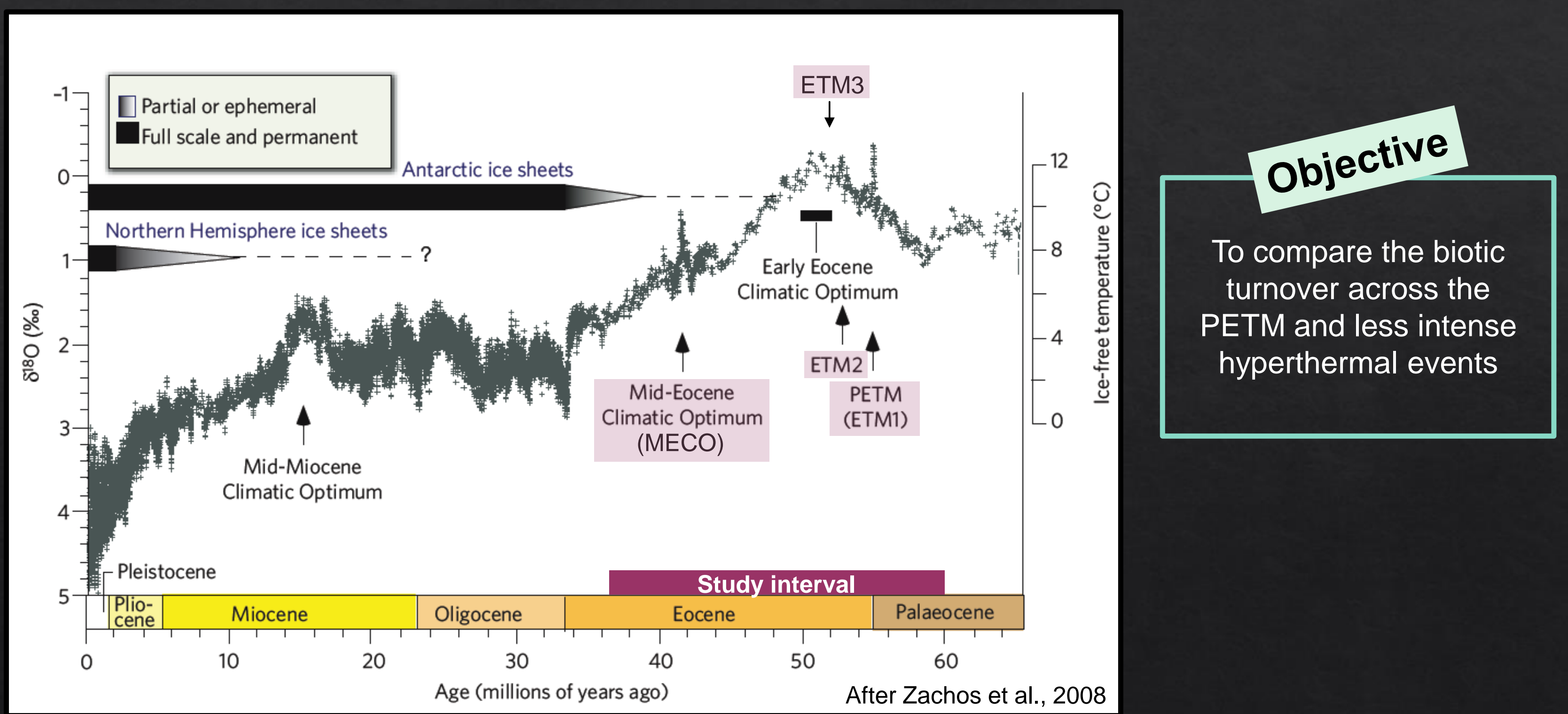


\section{Ocean Drilling Program Site 865}

- Paleocene - middle Eocene

- Allison Guyot, a seamount in the equatorial Pacific

- Foraminiferal nannofossil ooze

- $\mathrm{CaCO}_{3}$ content: 92-98\%

$55.5 \mathrm{Ma}$

- Paleodepth: upper lower bathyal ( 1300-1500 m)
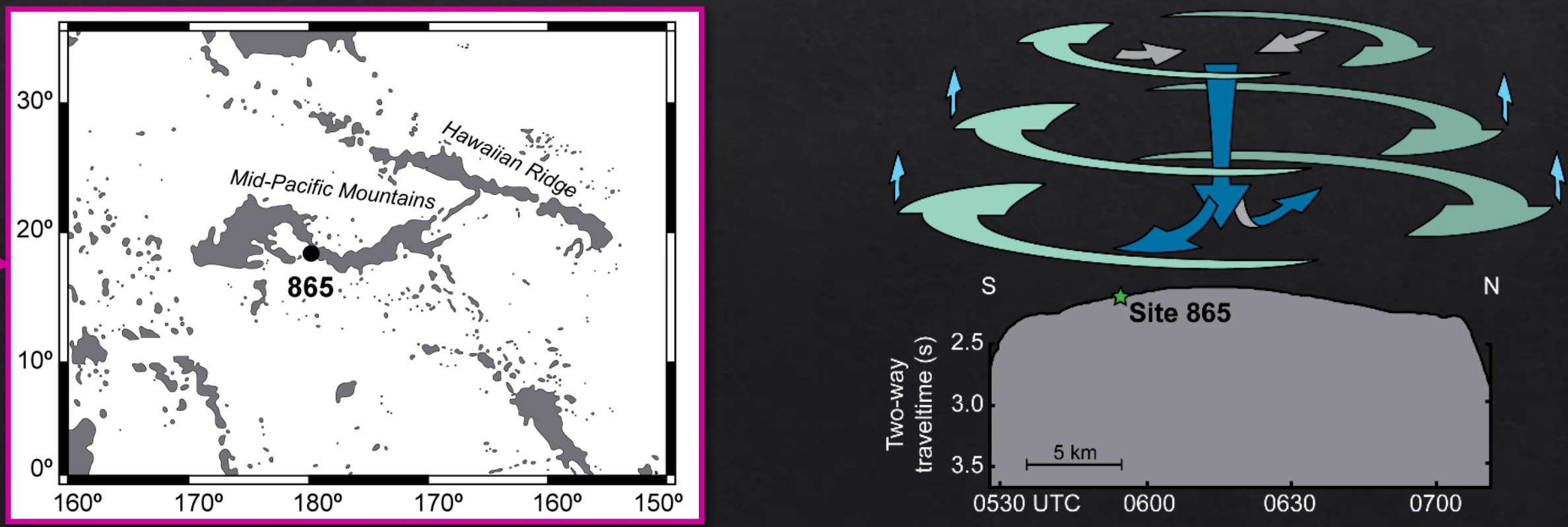


\section{Seamounts}
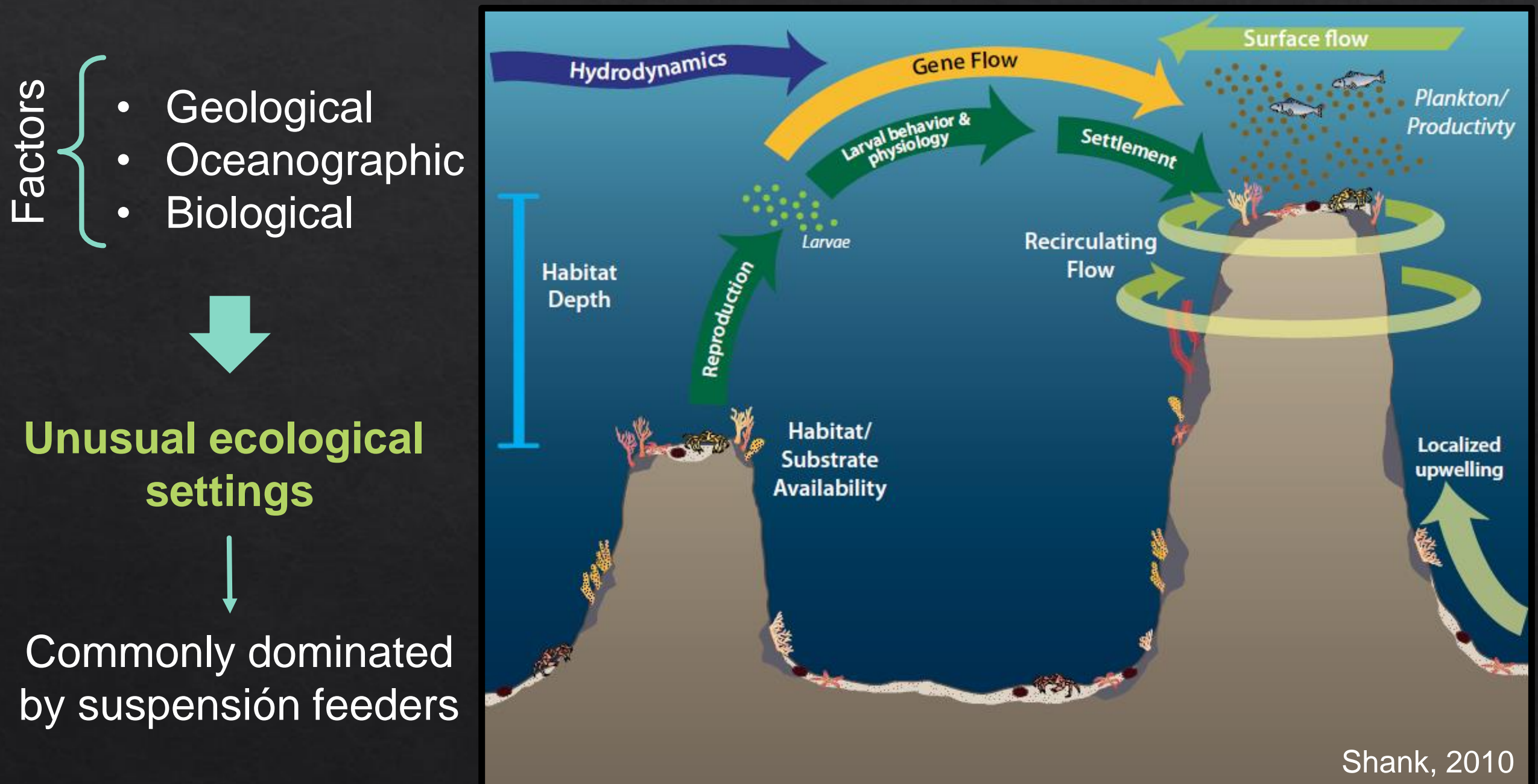

Currents are intensified

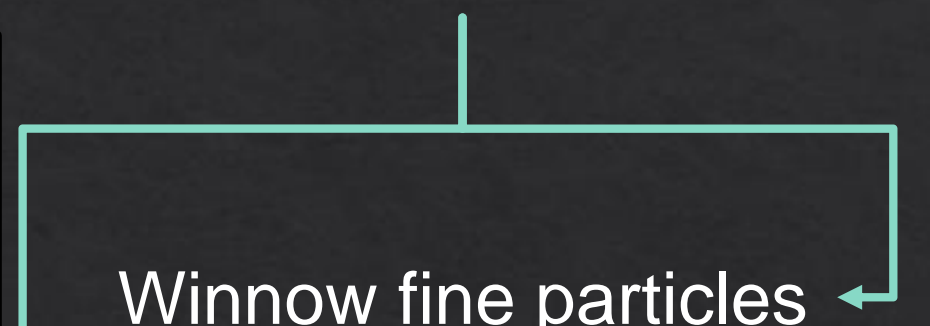

Winnow fine particles

Trap organisms and food particles (larger)

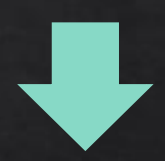

The link between primary productivity and arrival of food to the seafloor (bentho-pelagic coupling) may be broken 


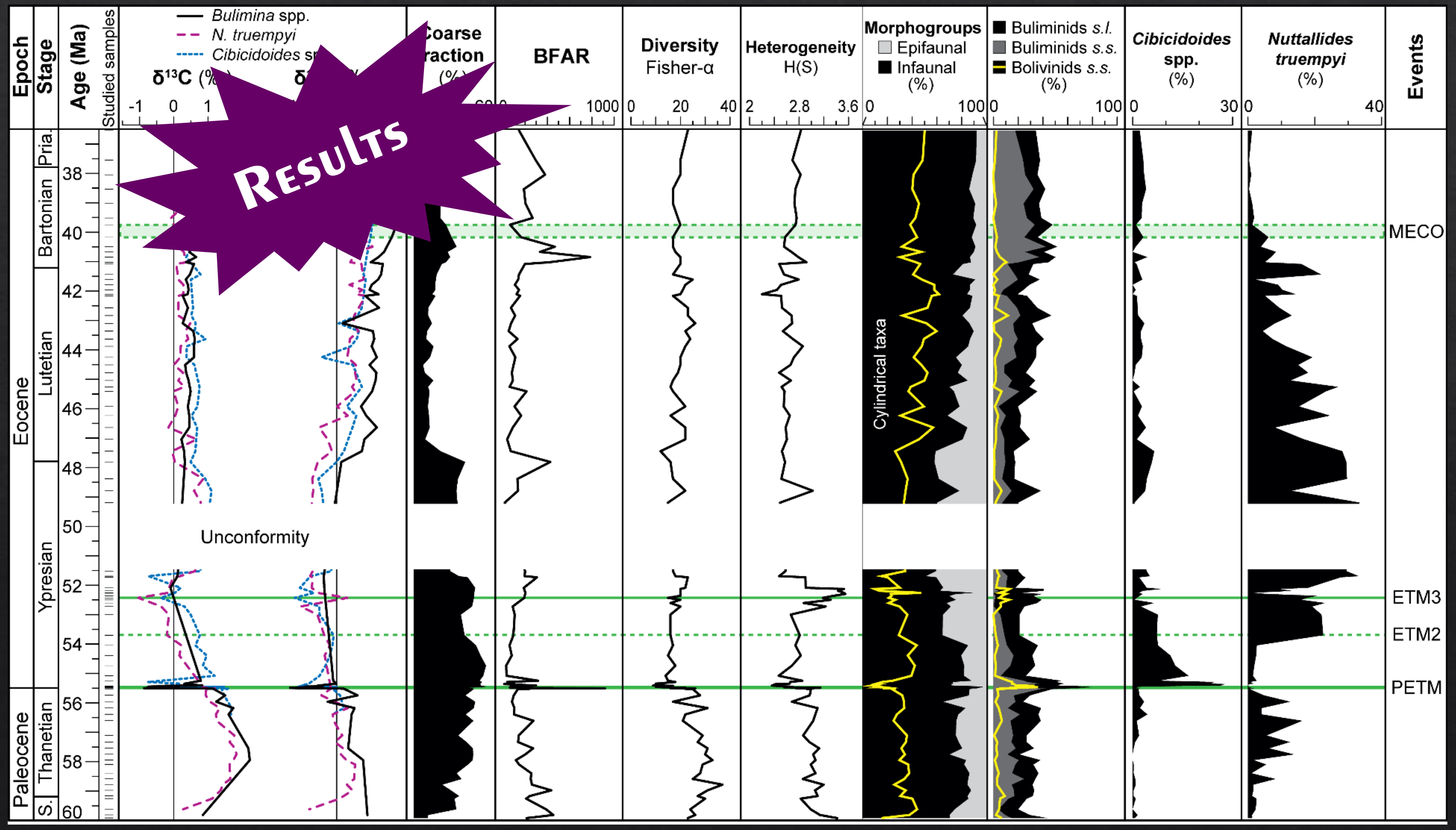


Results

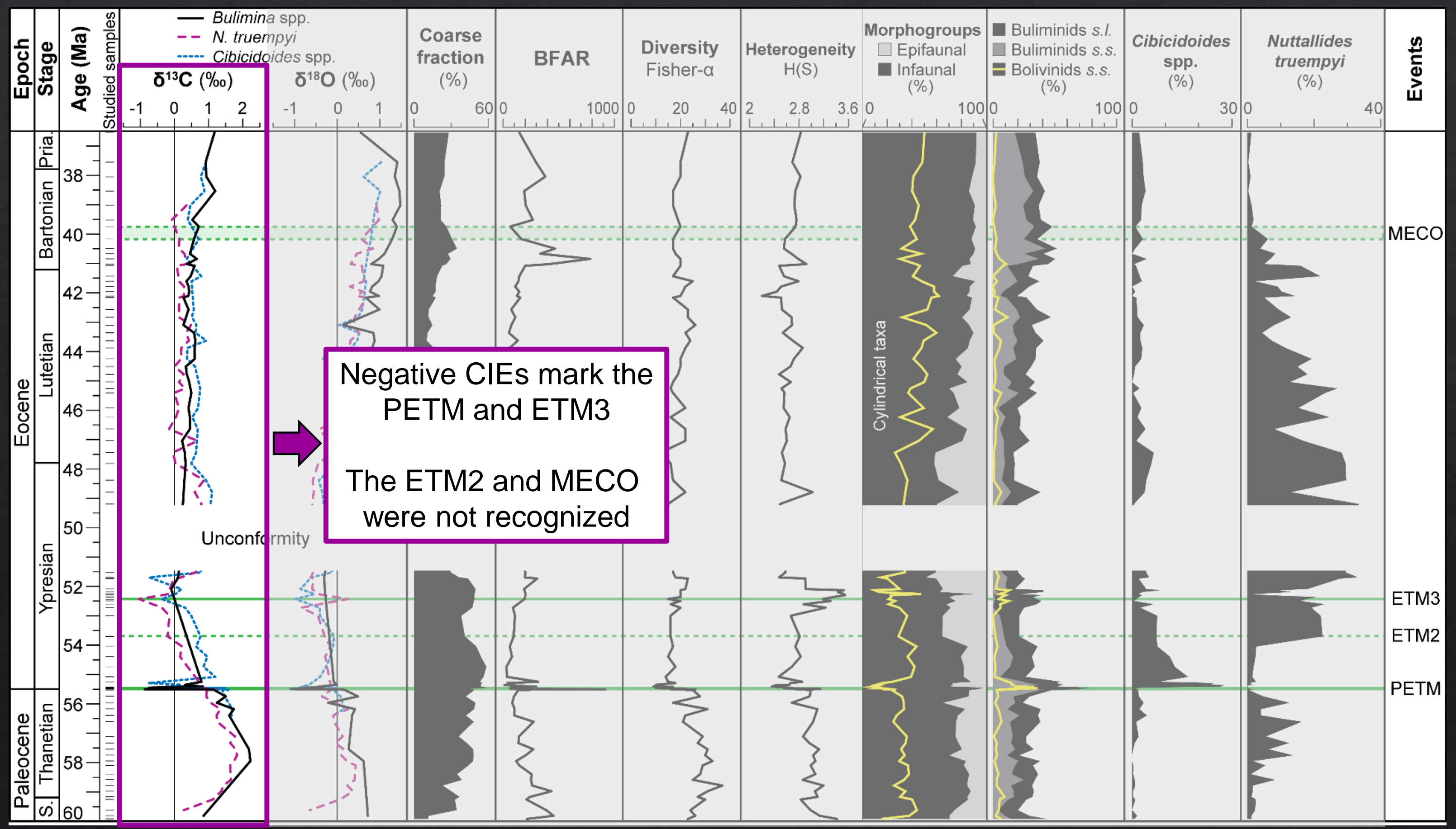


Results

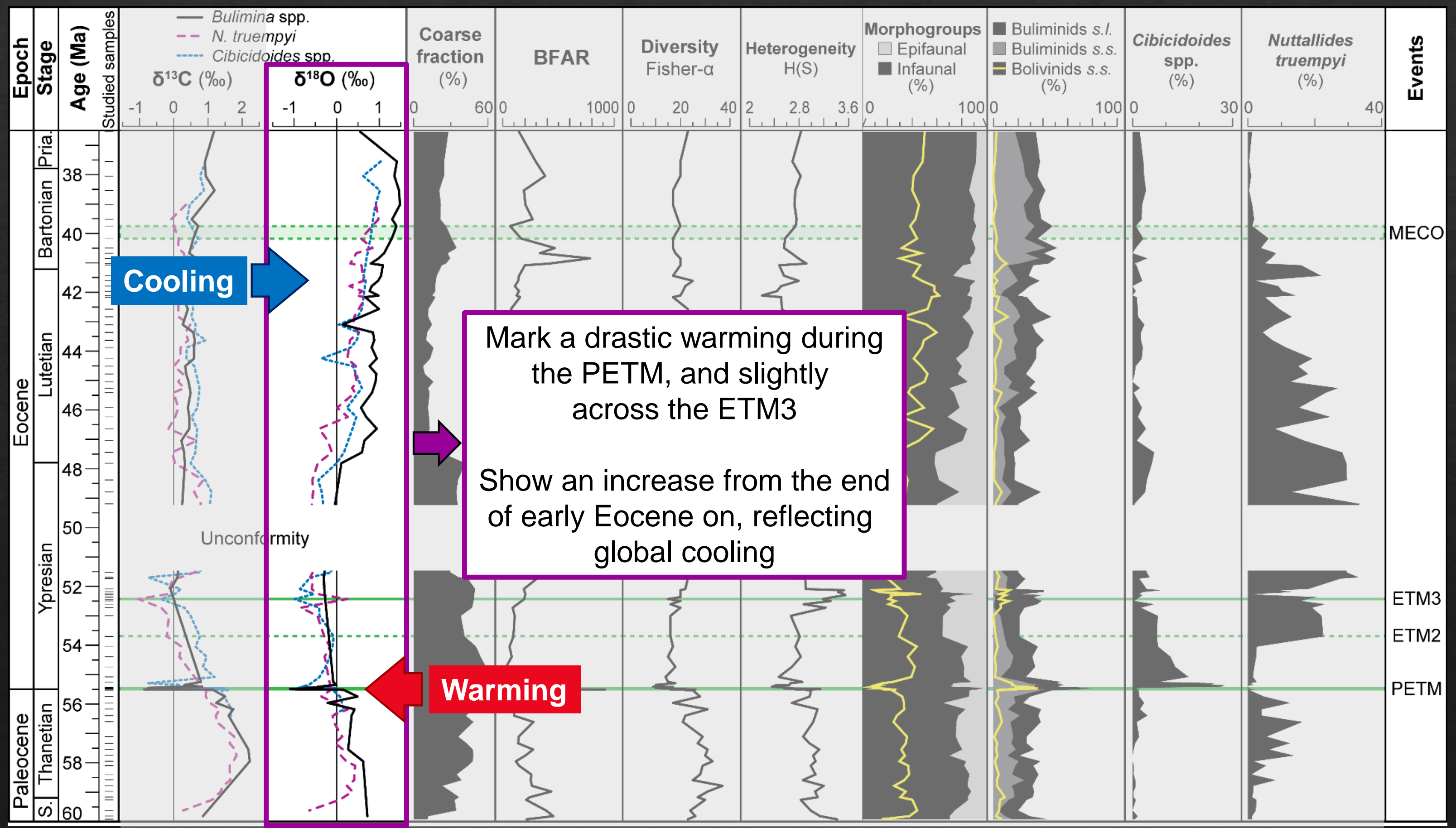


Results

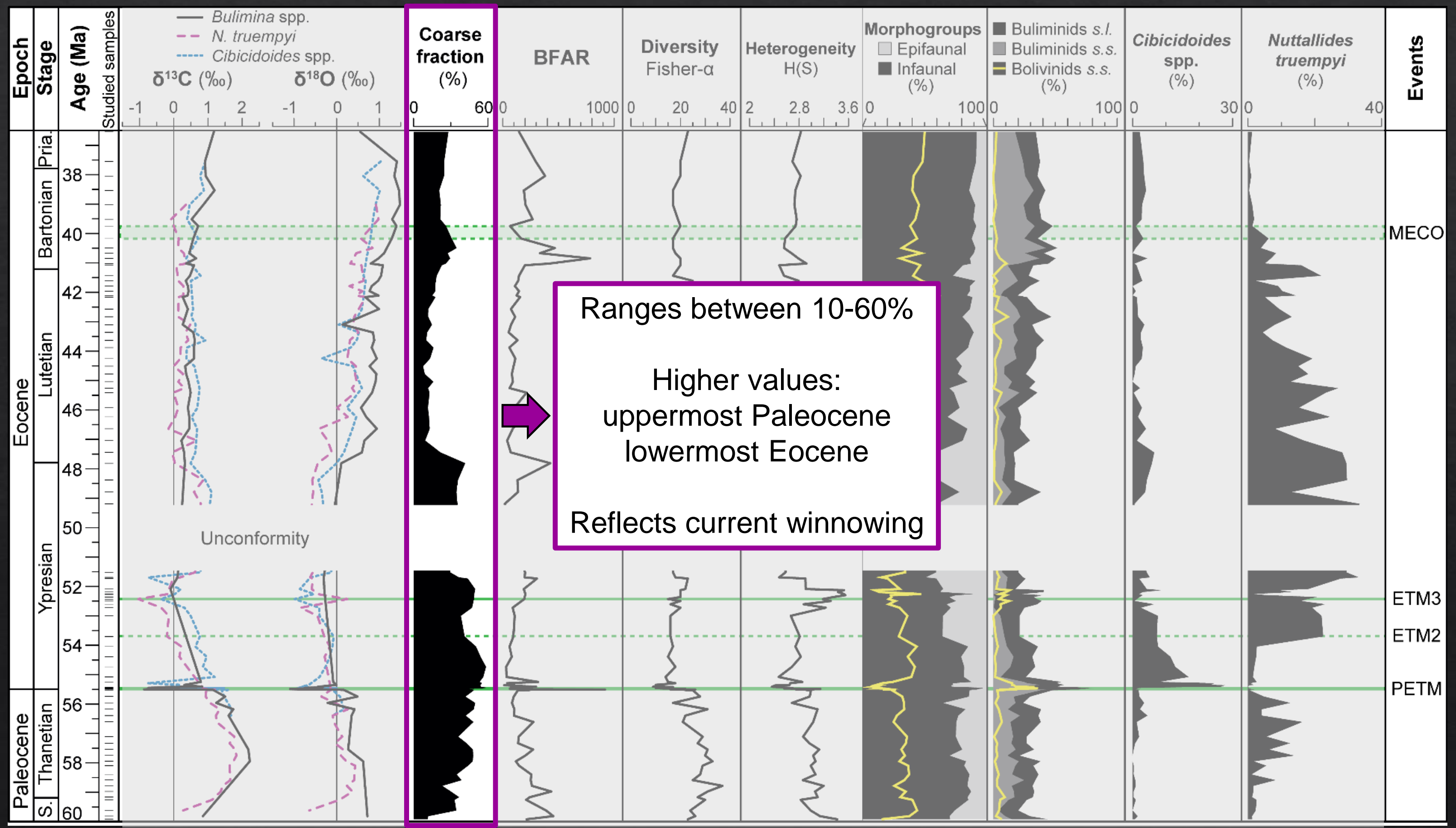




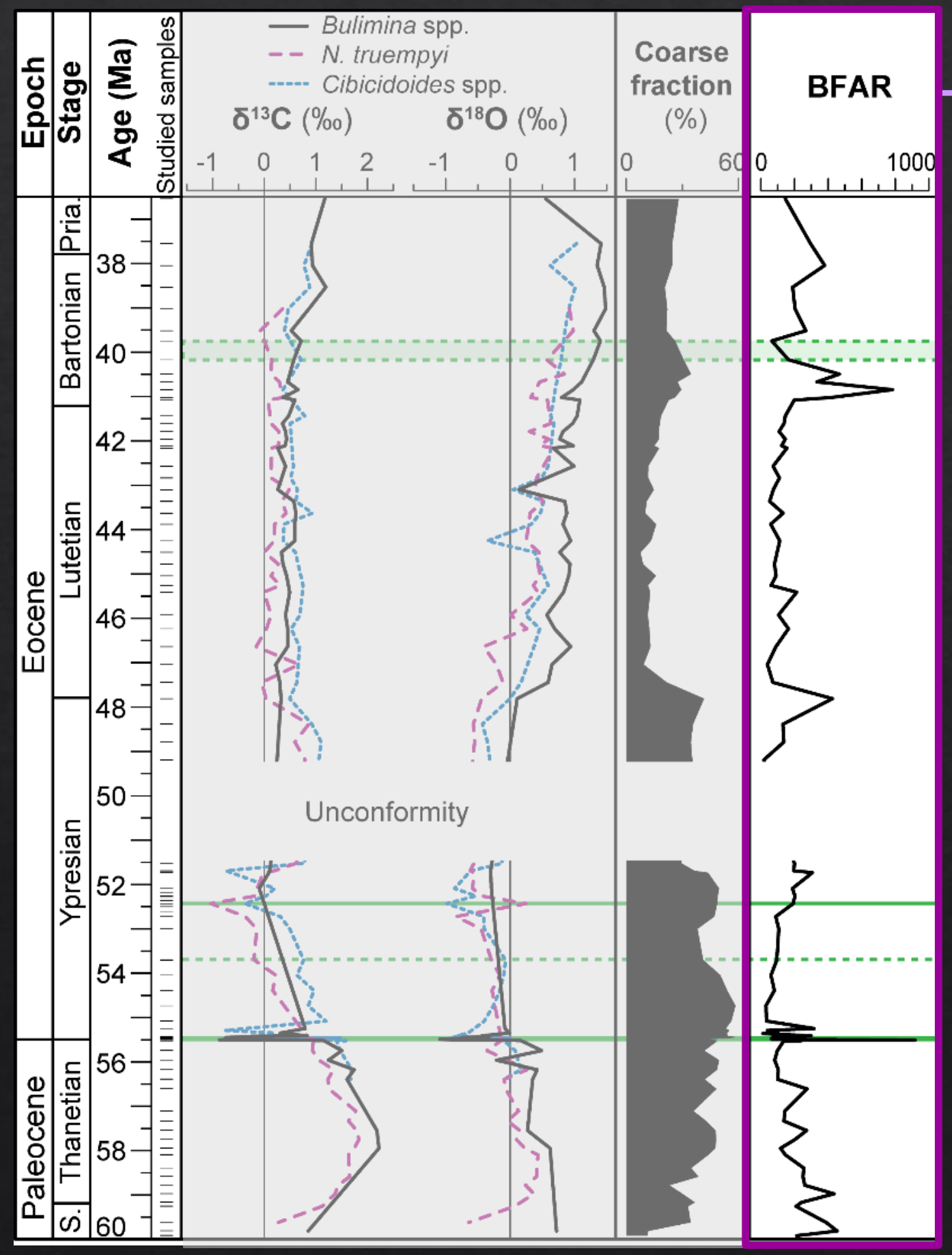

\section{Benthic Foraminiferal Accumulation Rates}

Number of benthic foraminifera per $\mathrm{cm}^{2}$ per thousand years<smiles>[3H][CH]</smiles>

Proxy for export productivity (higher numbers indicating more organic carbon reaching the seafloor) 


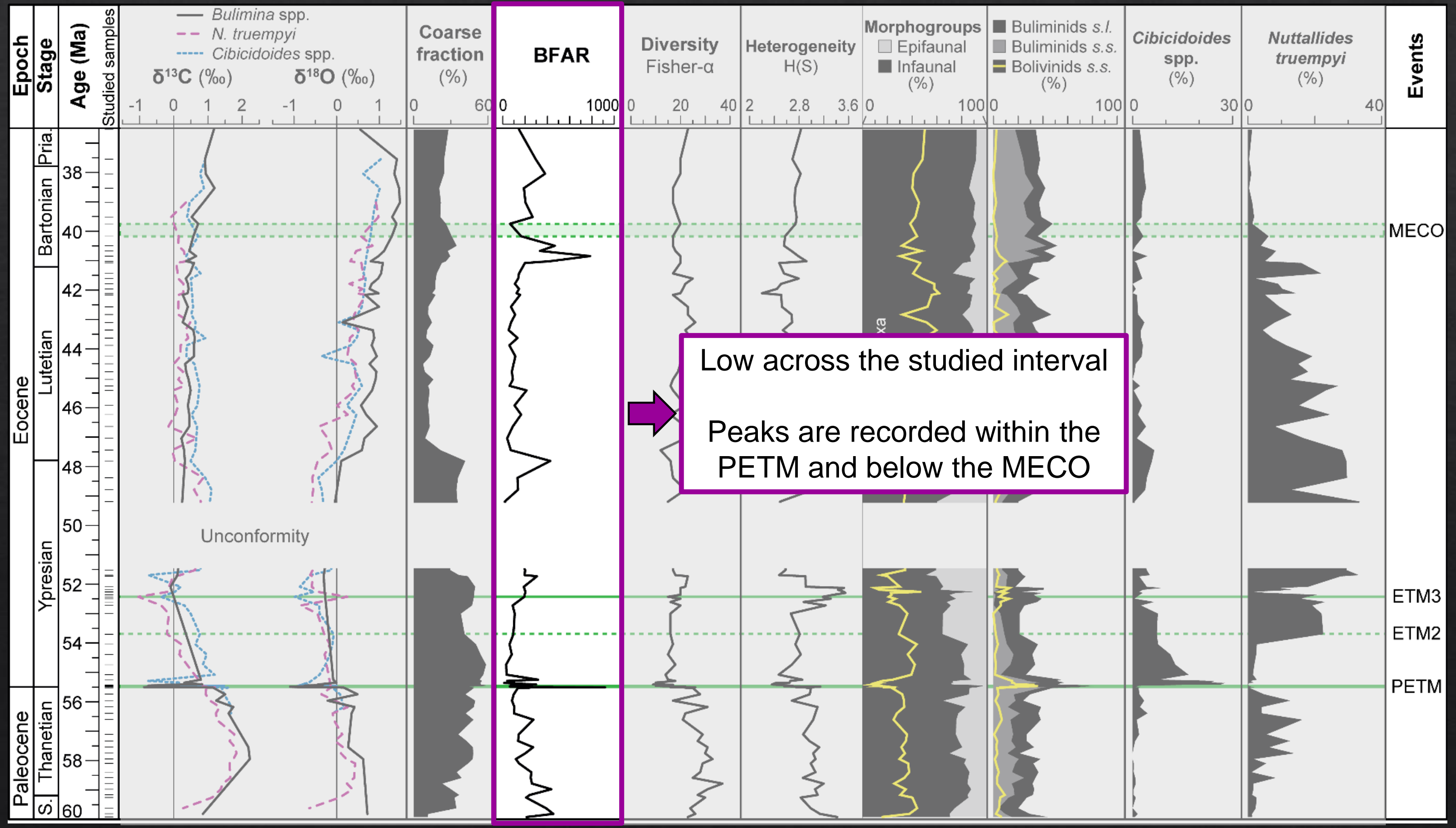




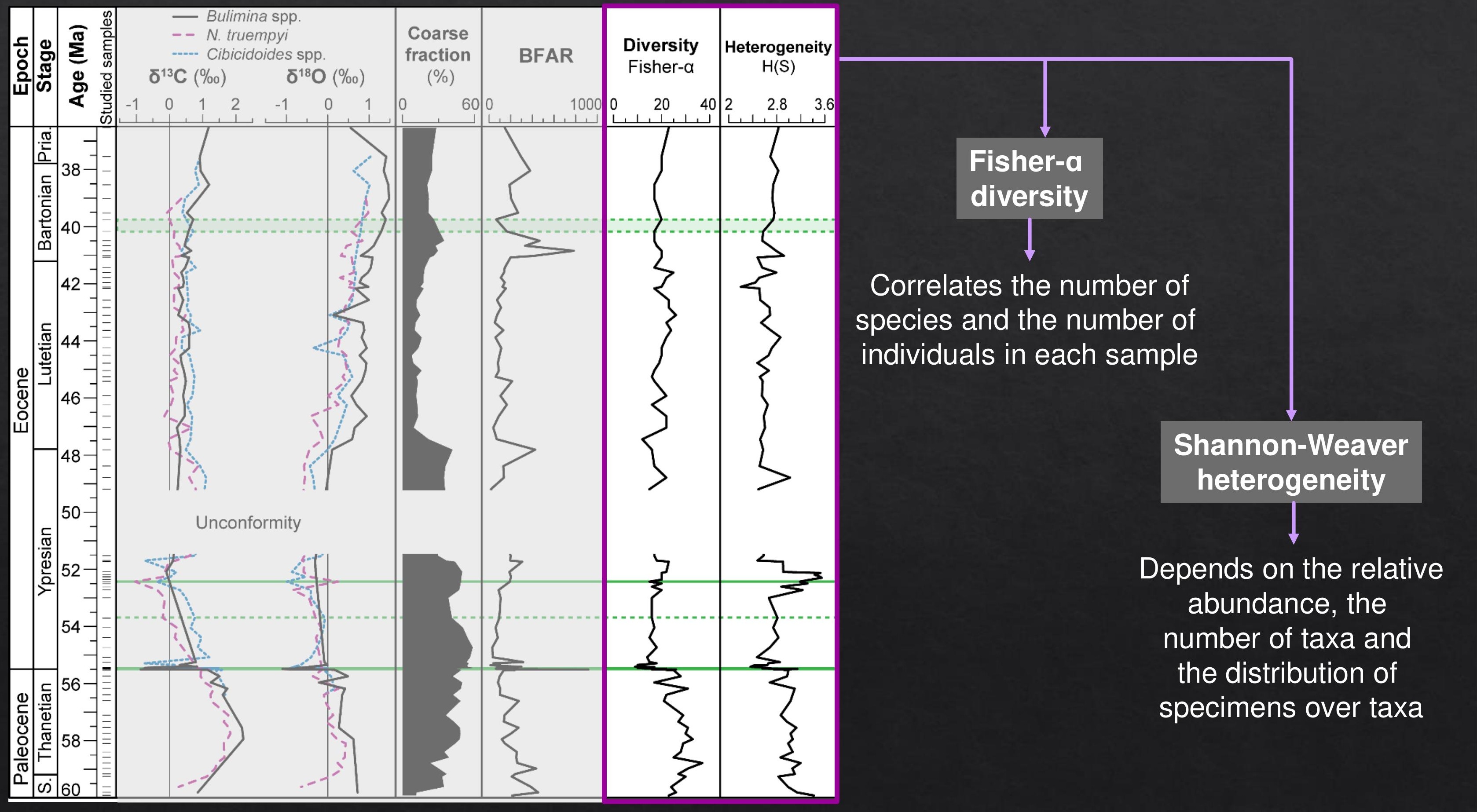




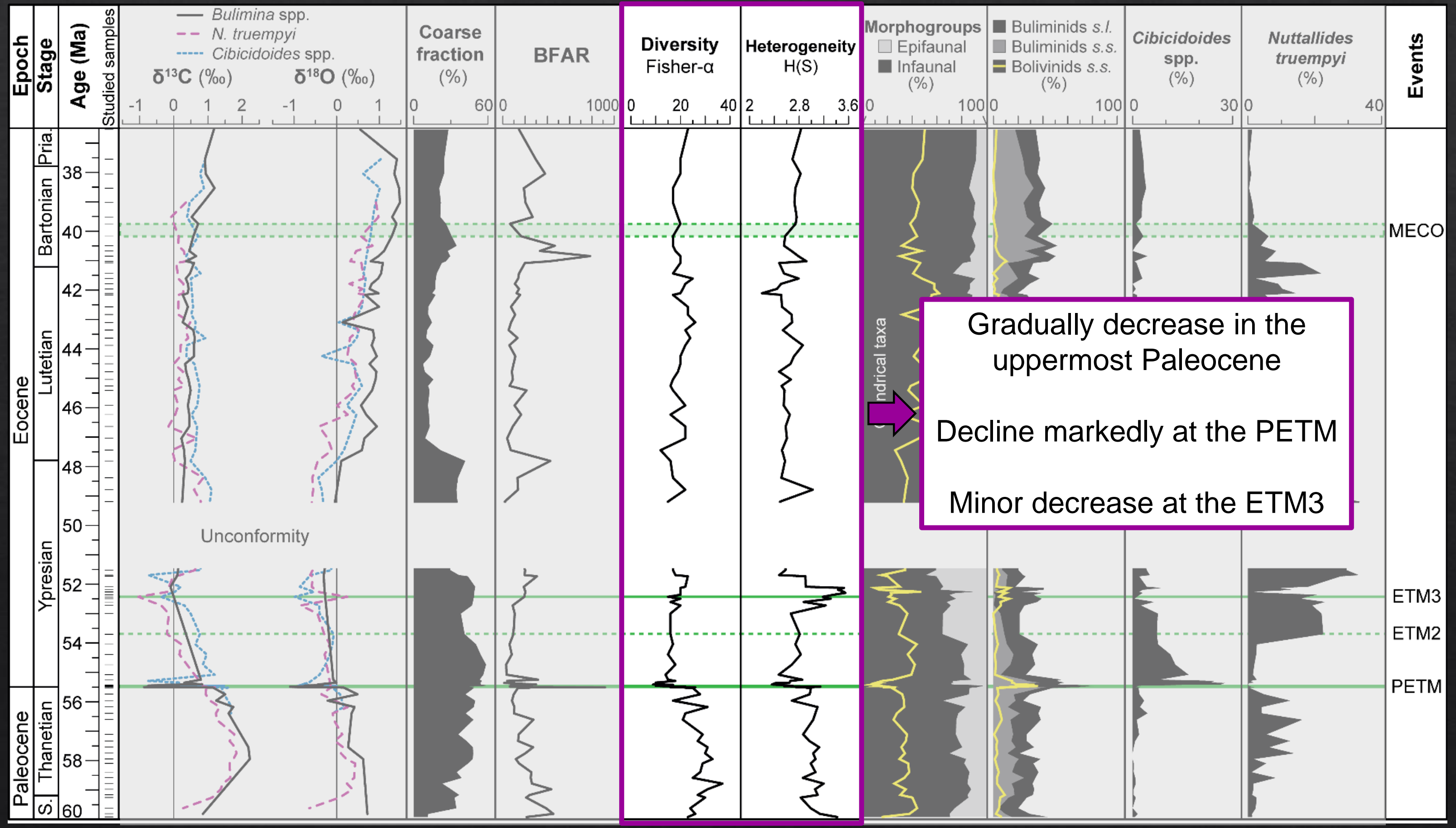


Results

TROX model

(Jorissen et al., 1995)

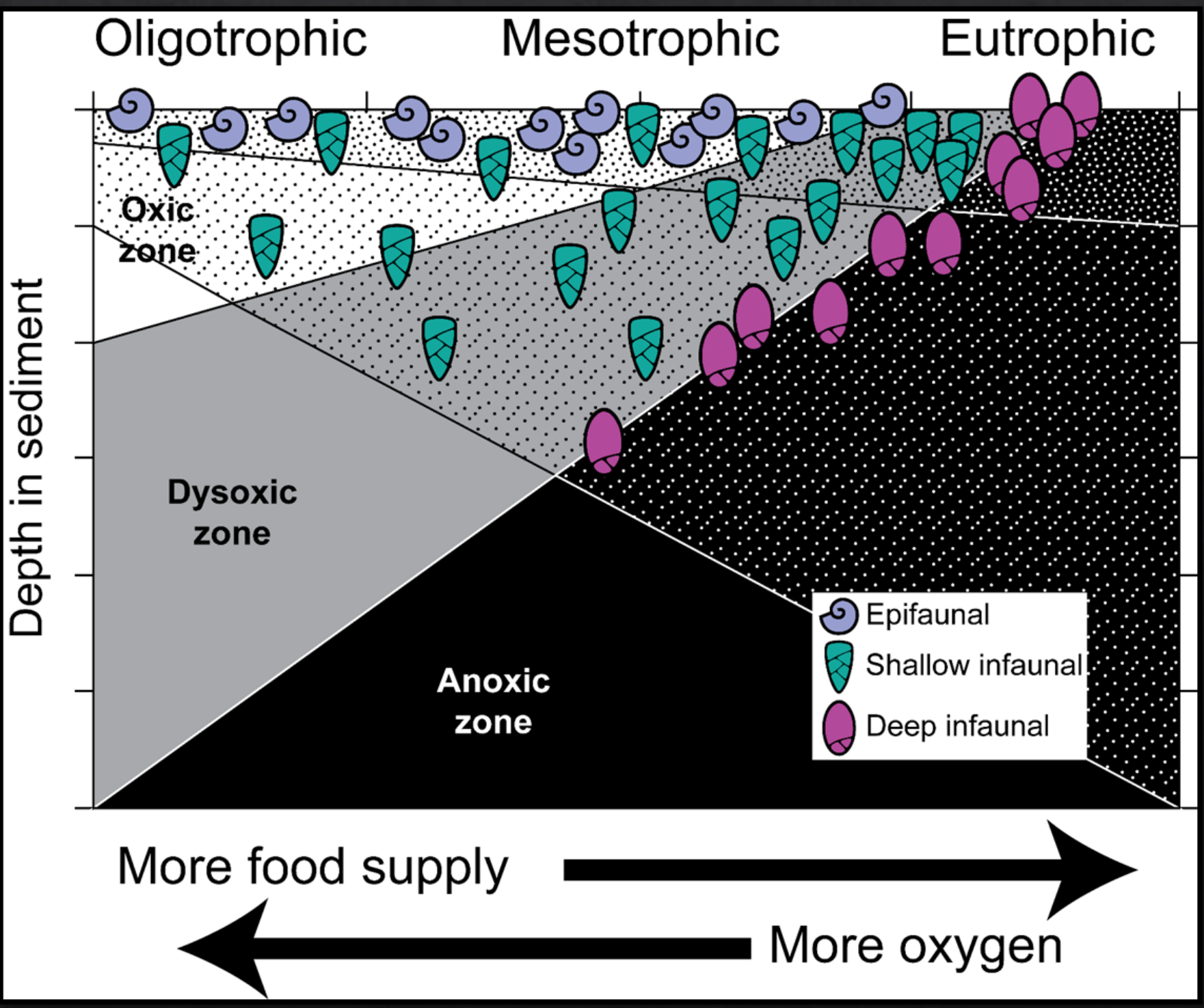

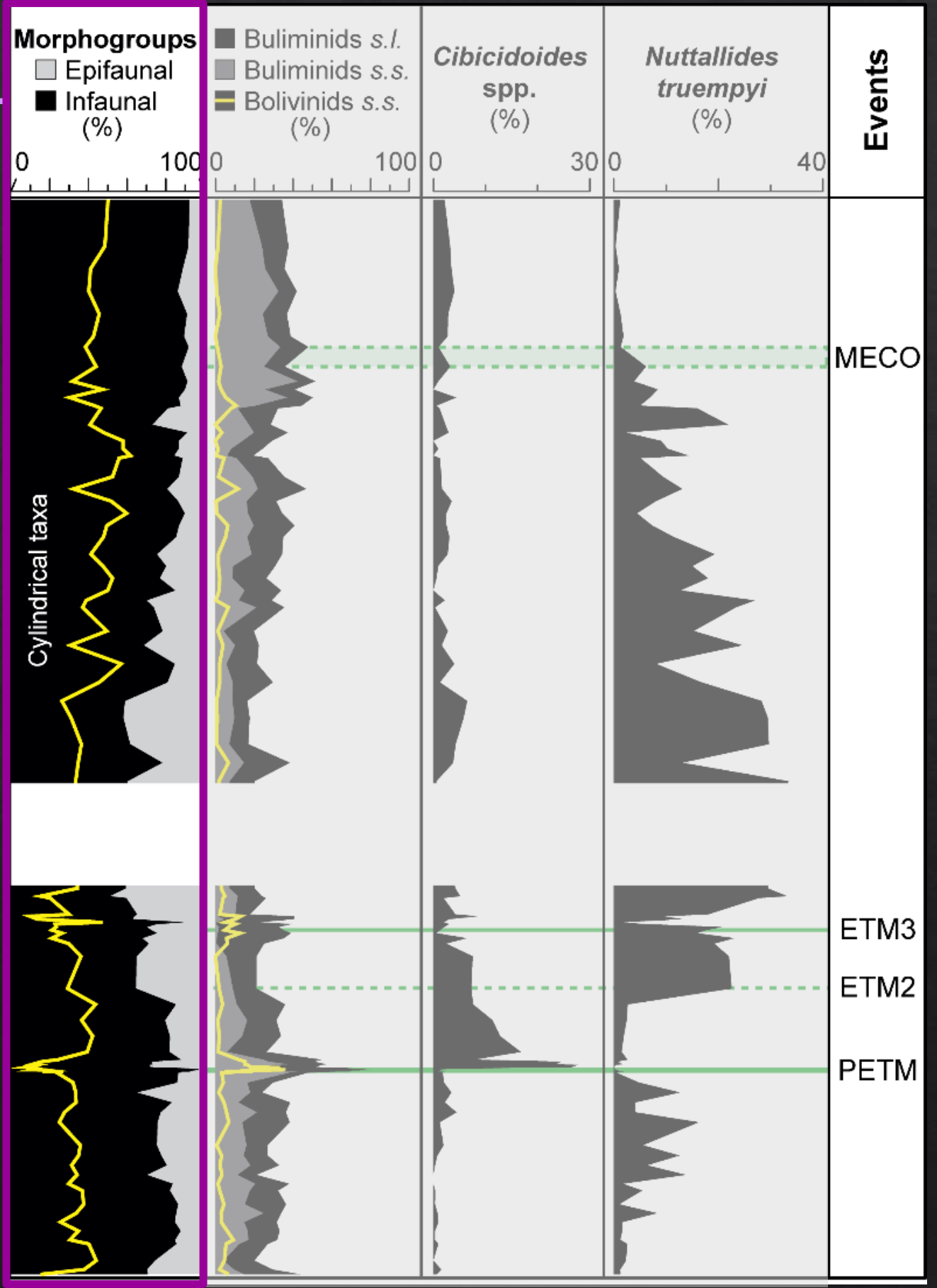


Results

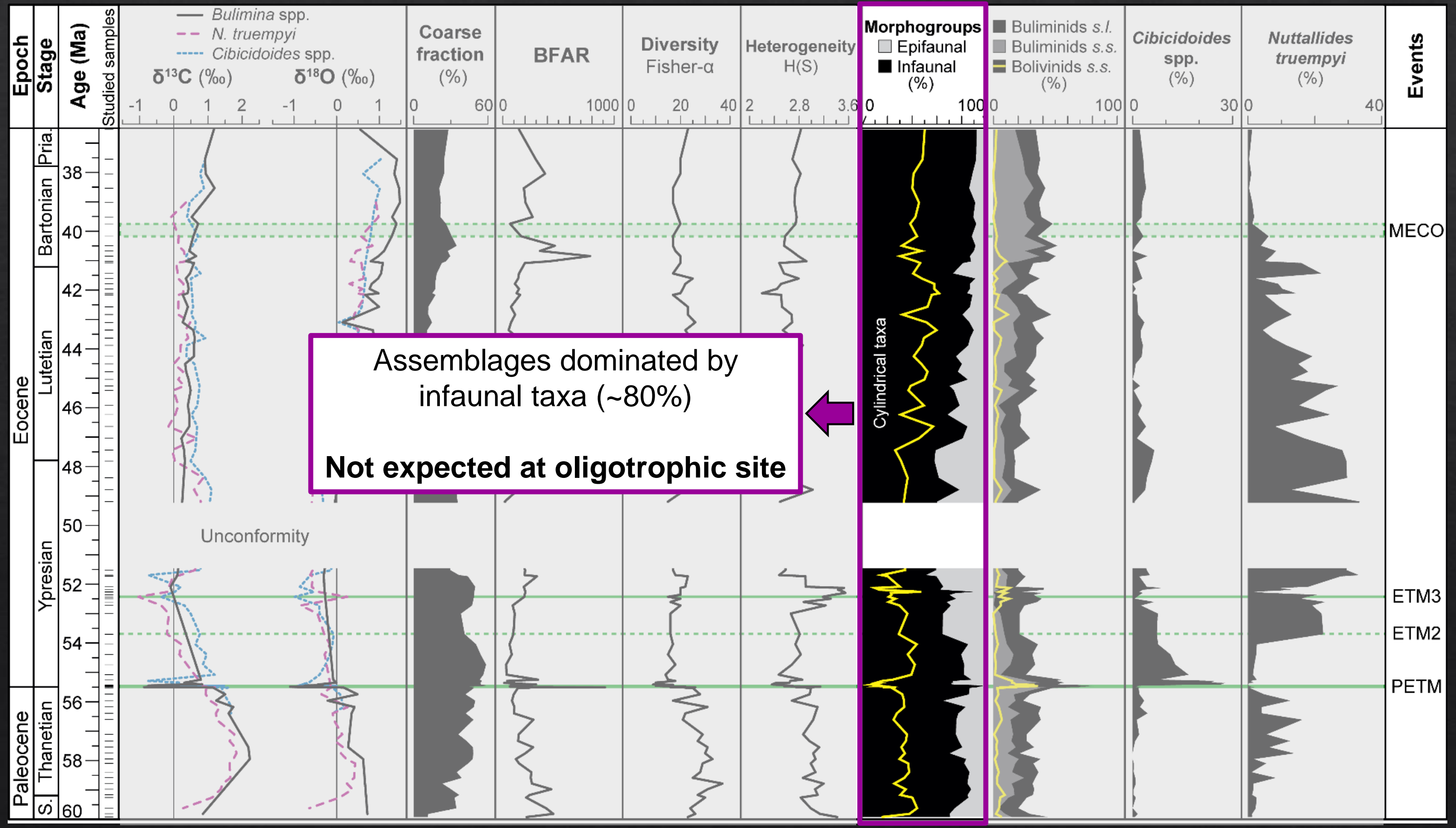


Results

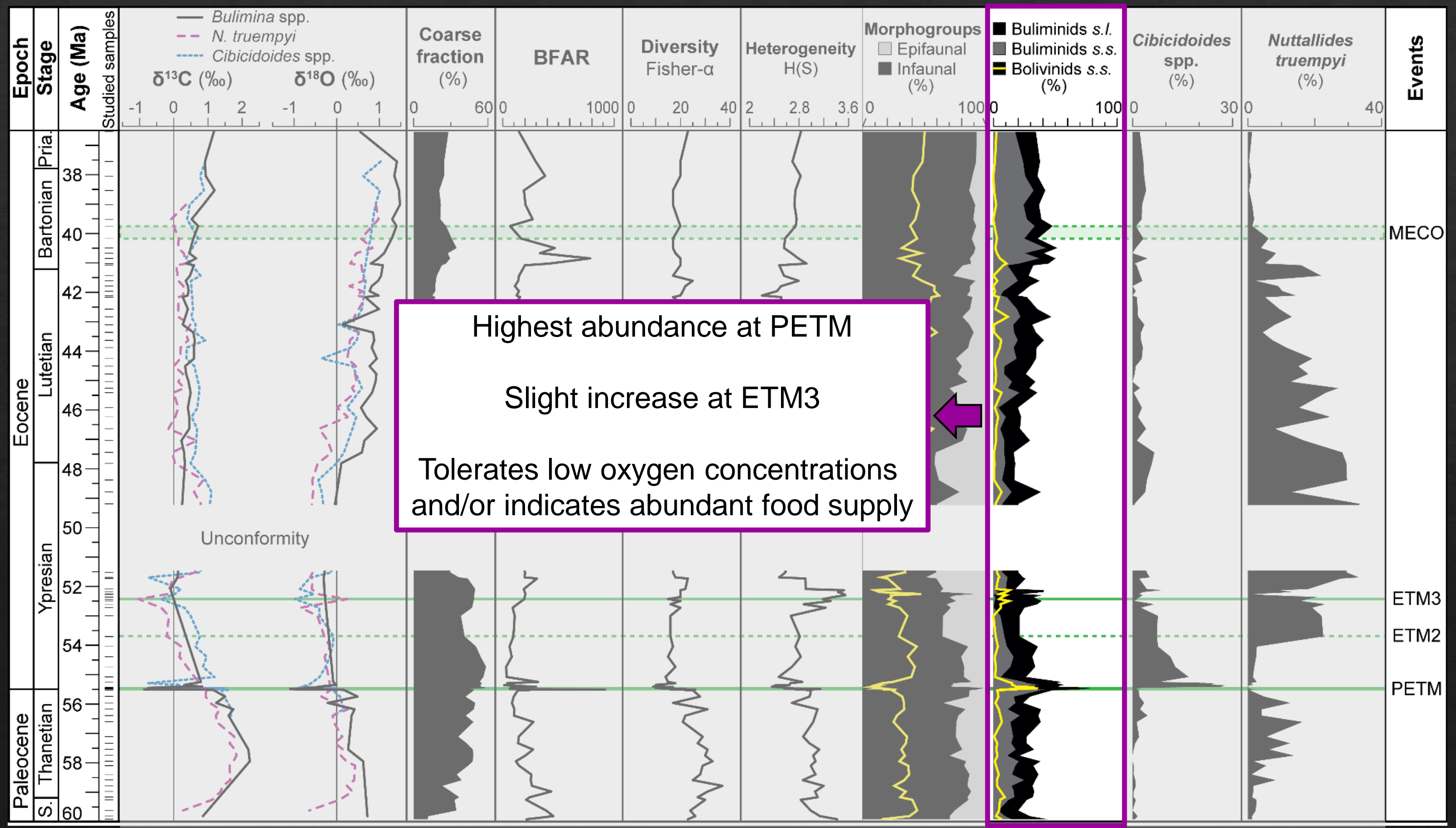


Results

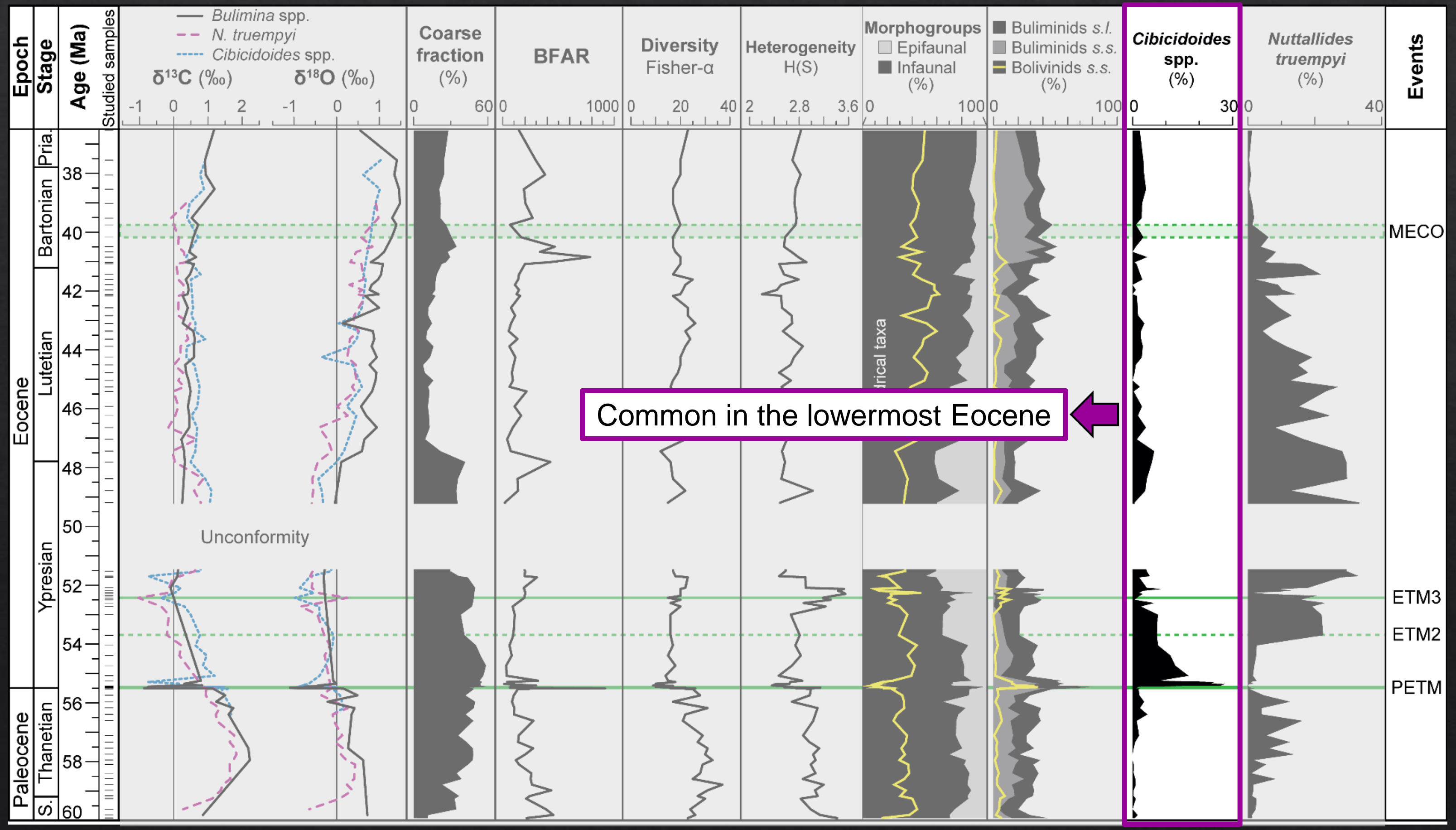




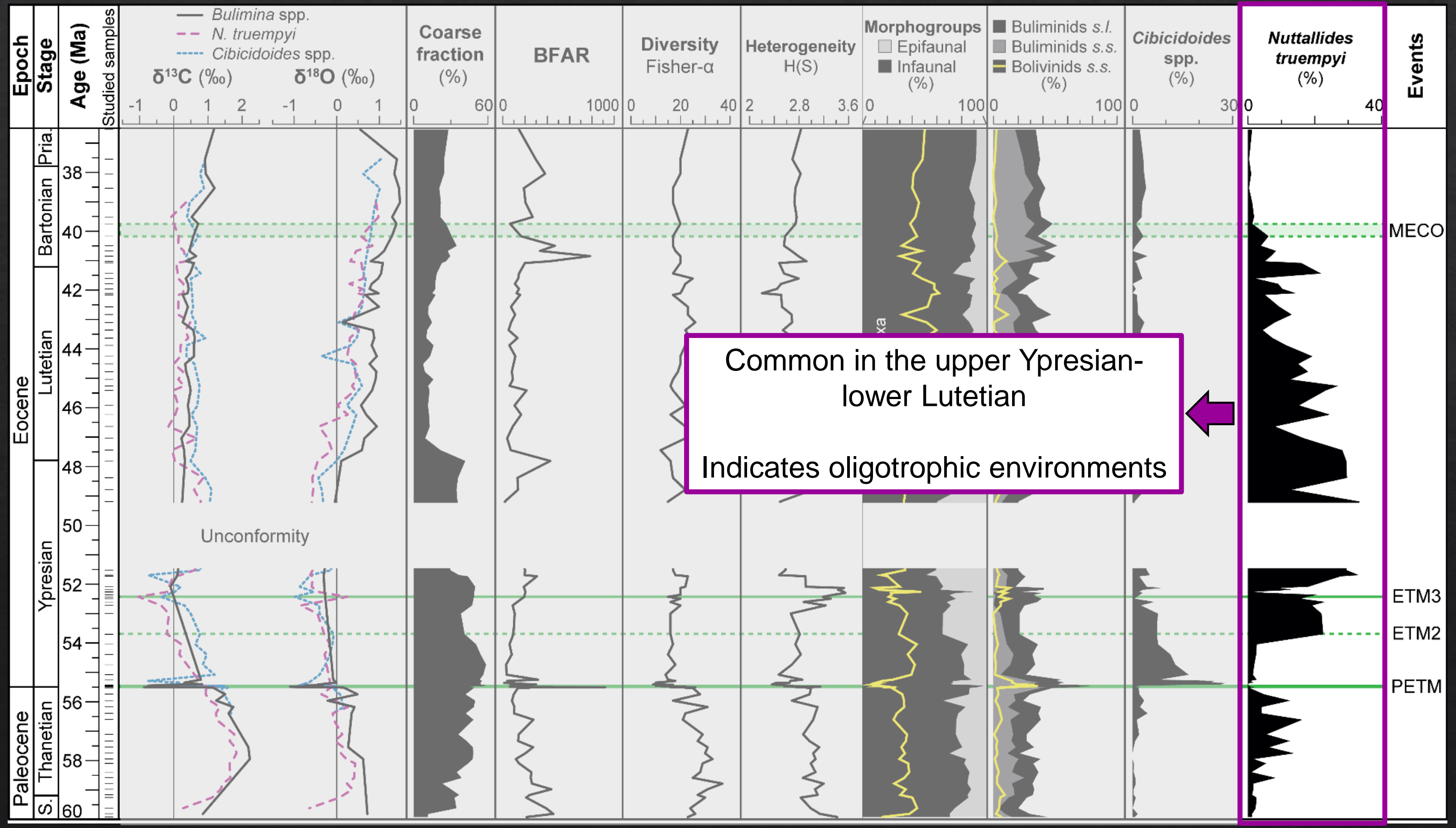


Coarse fraction negatively corrrelates with oxygen isotopes

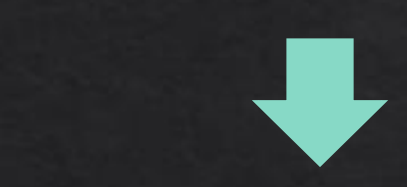

Increased winnowing ocurred during warm periods
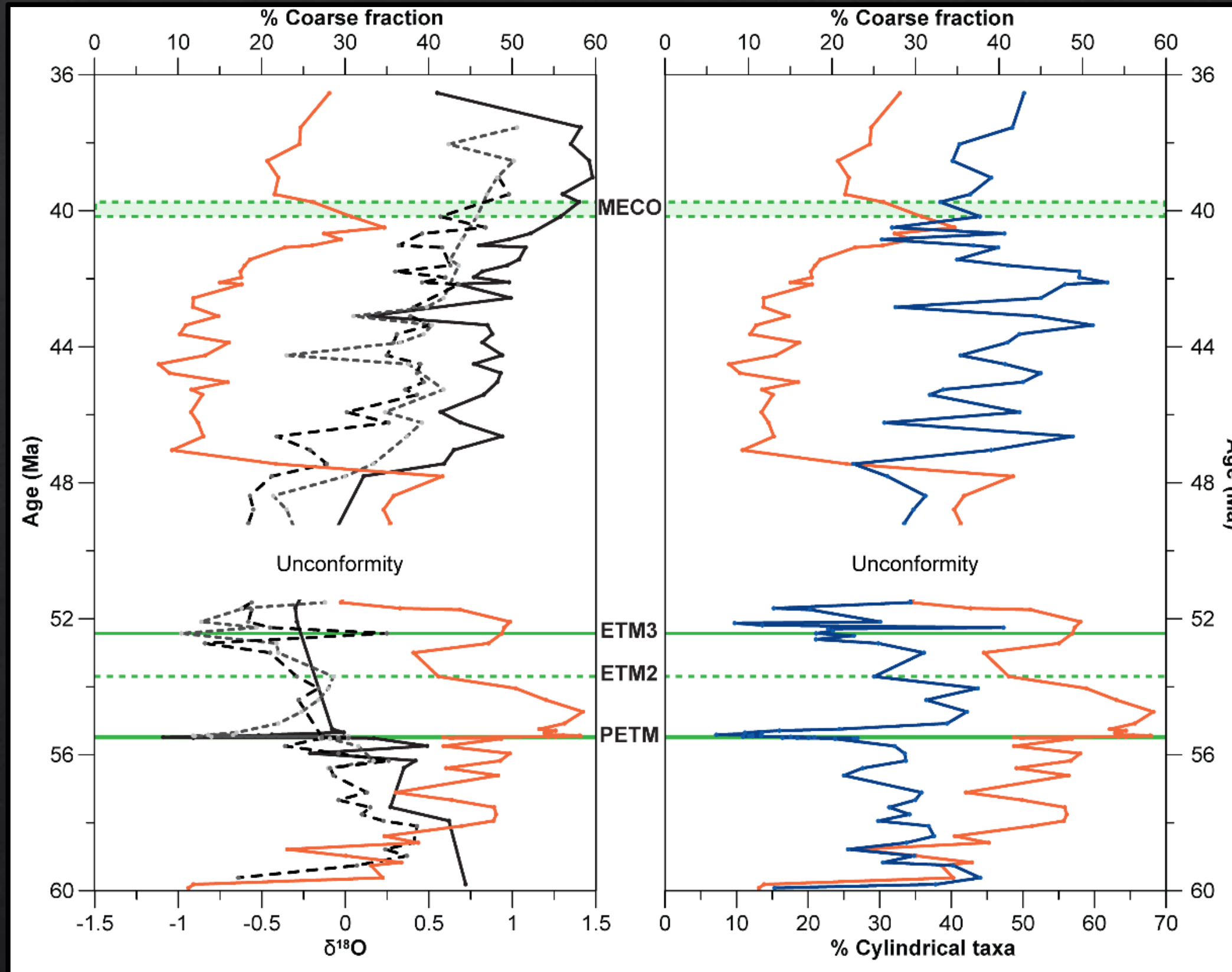

$\delta^{18} \mathrm{O}$ Bulimina spp.

$--\delta^{18} \mathrm{O}$ N. truempyi

$-\delta^{18} \mathrm{O}$ Cibicidoides spp

Coarse fraction
Success of cylindrical taxa in current-swept environments

Less food supply 


\section{Paleocene - Eocene Thermal Maximum (PETM)}

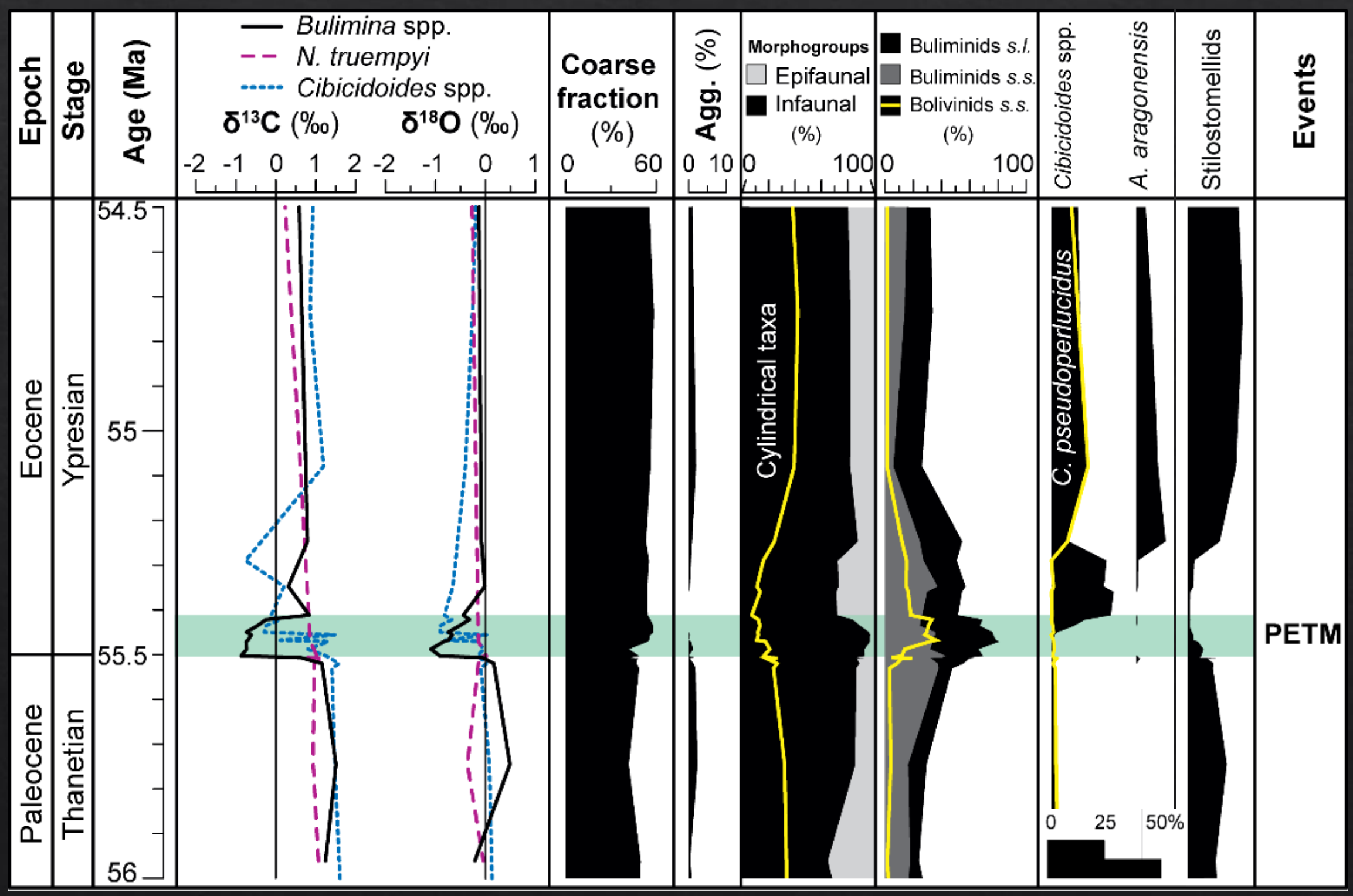

- $33.4 \%$ became extinct at the PETM

- Increase in carbonate dissolution

- Infaunal taxa are shielded from corrosive waters

- Increase in coarse fraction values point to increased currents

- Cibicidoides probably lived epifaunally attached to hard surfaces 


\section{Paleocene - Eocene Thermal Maximum (PETM)}

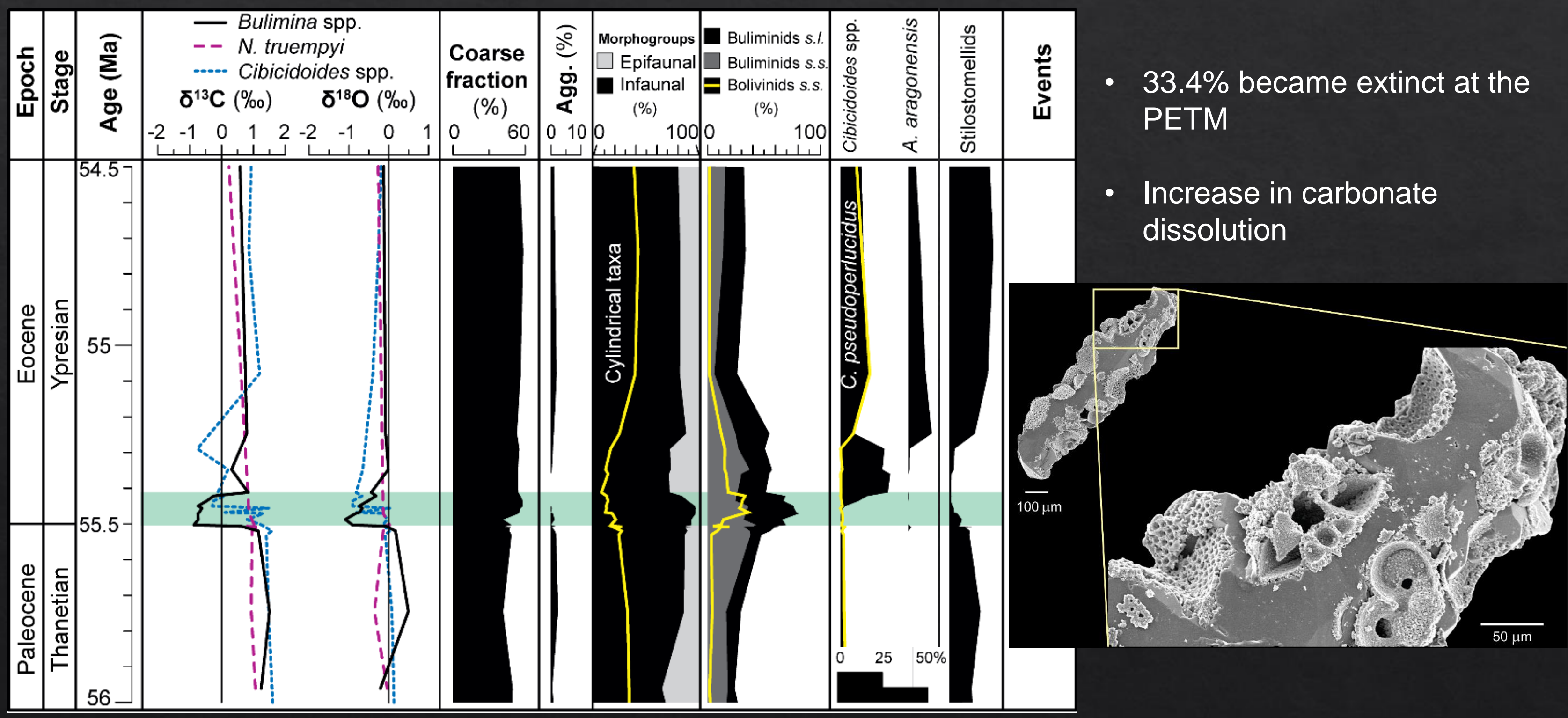




\section{Paleocene - Eocene Thermal Maximum (PETM)}

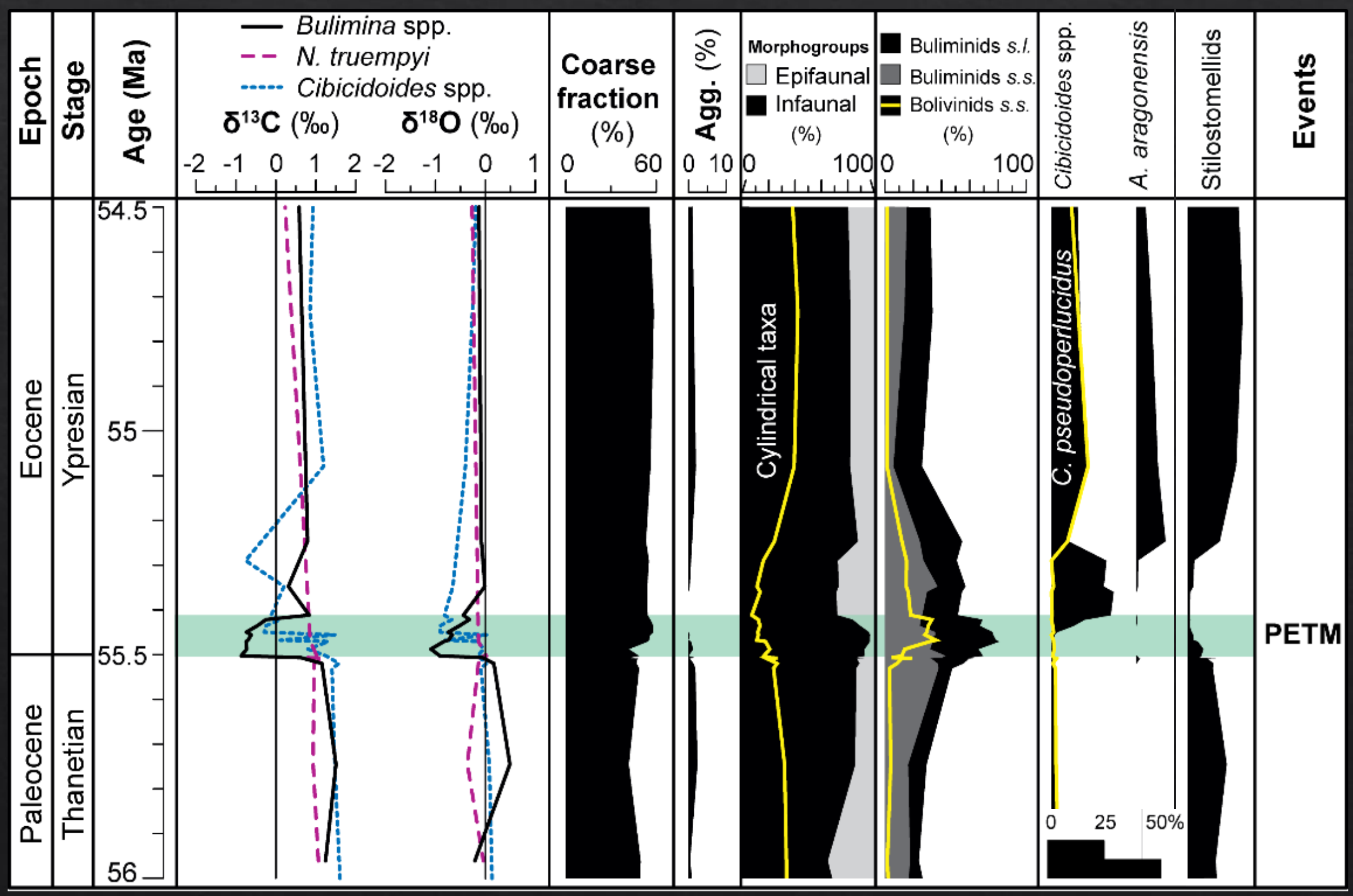

- $33.4 \%$ became extinct at the PETM

- Increase in carbonate dissolution

- Infaunal taxa are shielded from corrosive waters

- Increase in coarse fraction values point to increased currents

- Cibicidoides probably lived epifaunally attached to hard surfaces 


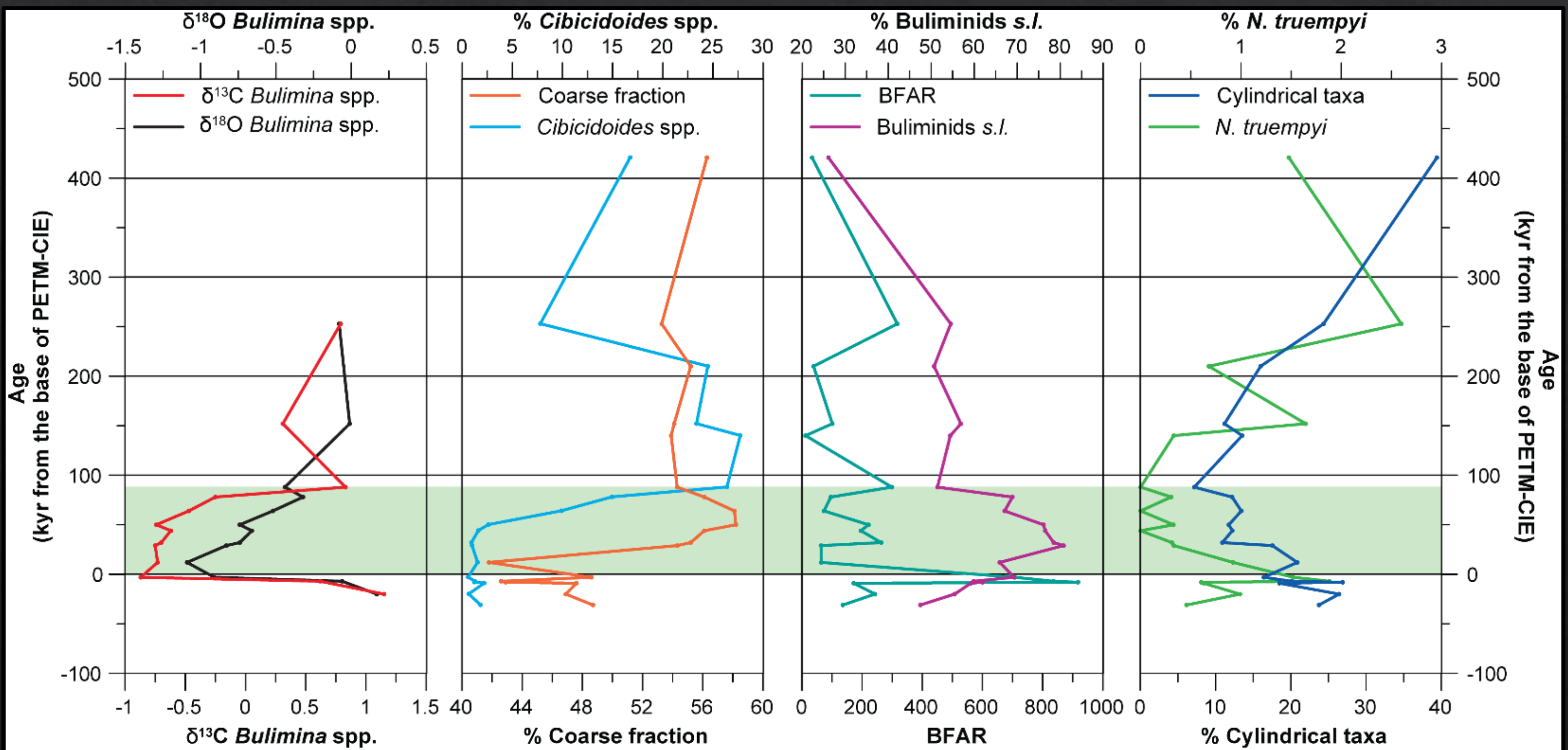




\section{Eocene Thermal Maximum 3 (ETM3)}

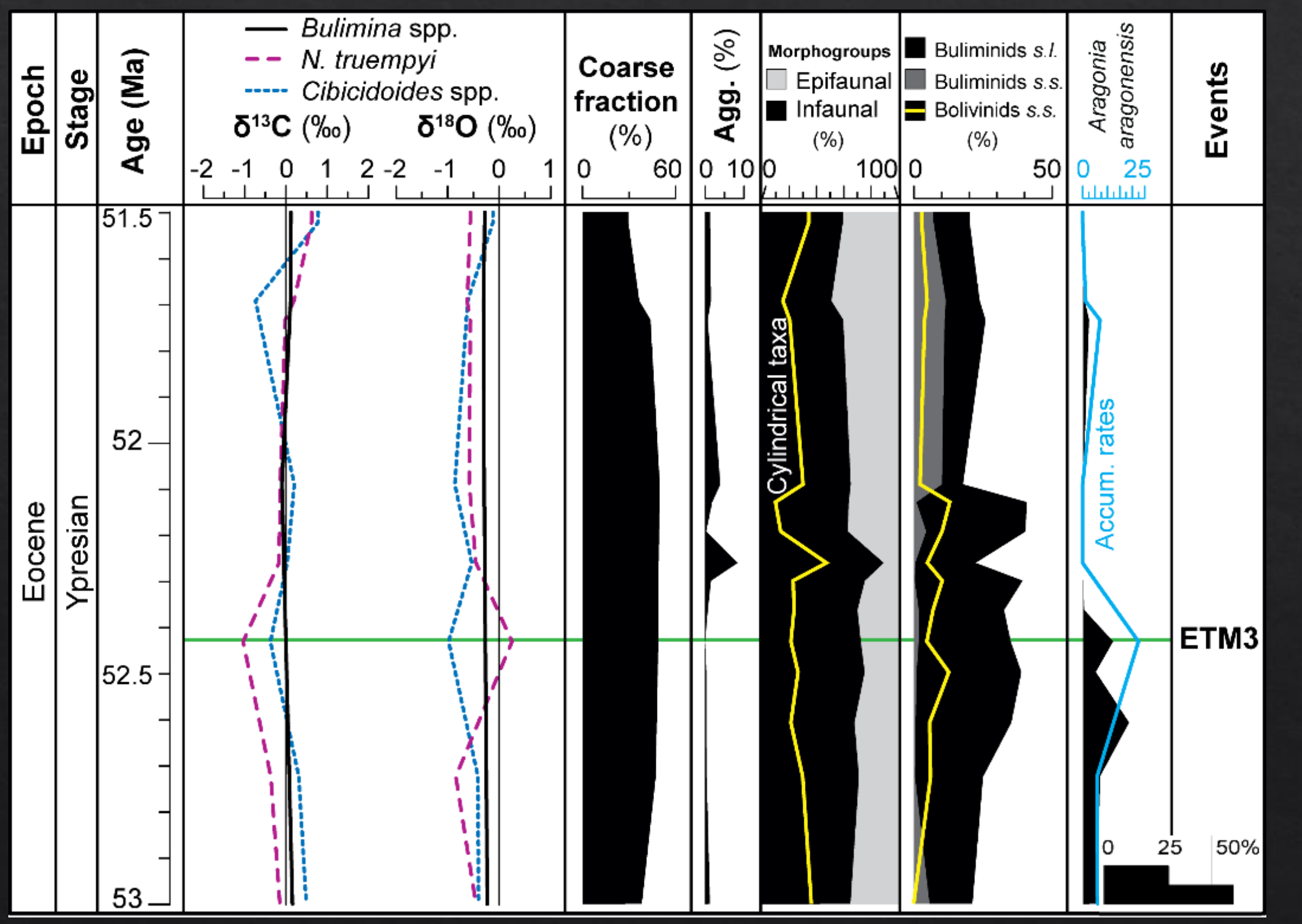

- No significant extinction has been documented

- Significant dissolution has not occurred

- Increase in buliminids suggests moderate increase in food supply

- A. aragonensis: opportunistic species, marker of hyperthermals

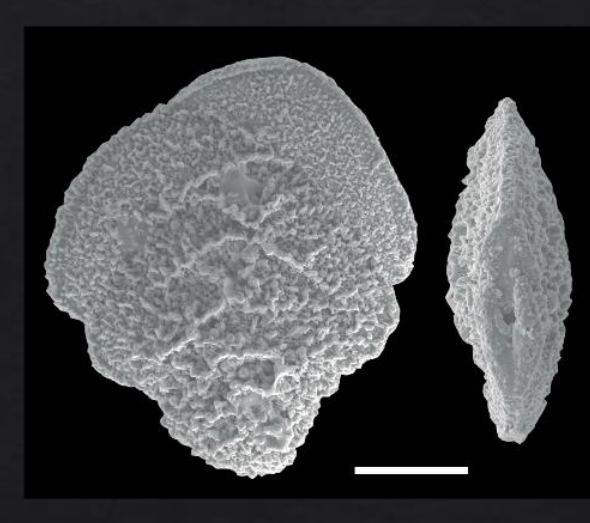




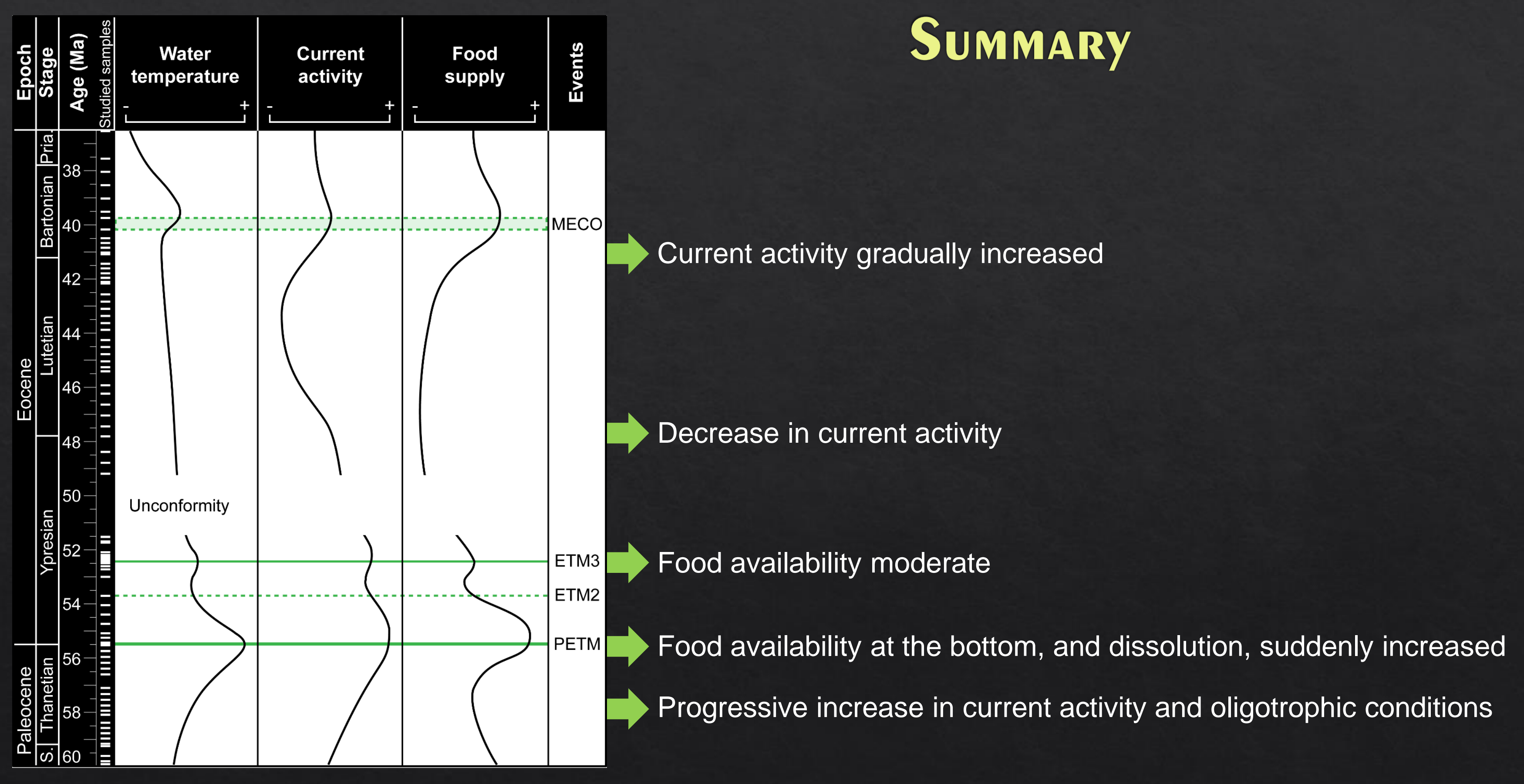




\section{Conclusions}

- Assemblage changes across the PETM and ETM3 were similar.

- Both events possibly associated with increased food availability through trophic focusing due to enhanced current activity.

- Faunas across PETM have been also affected by carbonate dissolution, but not across ETM3.

- The biotic response scales with the magnitude of the event.

- Currents around seamounts may break the bentho-pelagic coupling. 


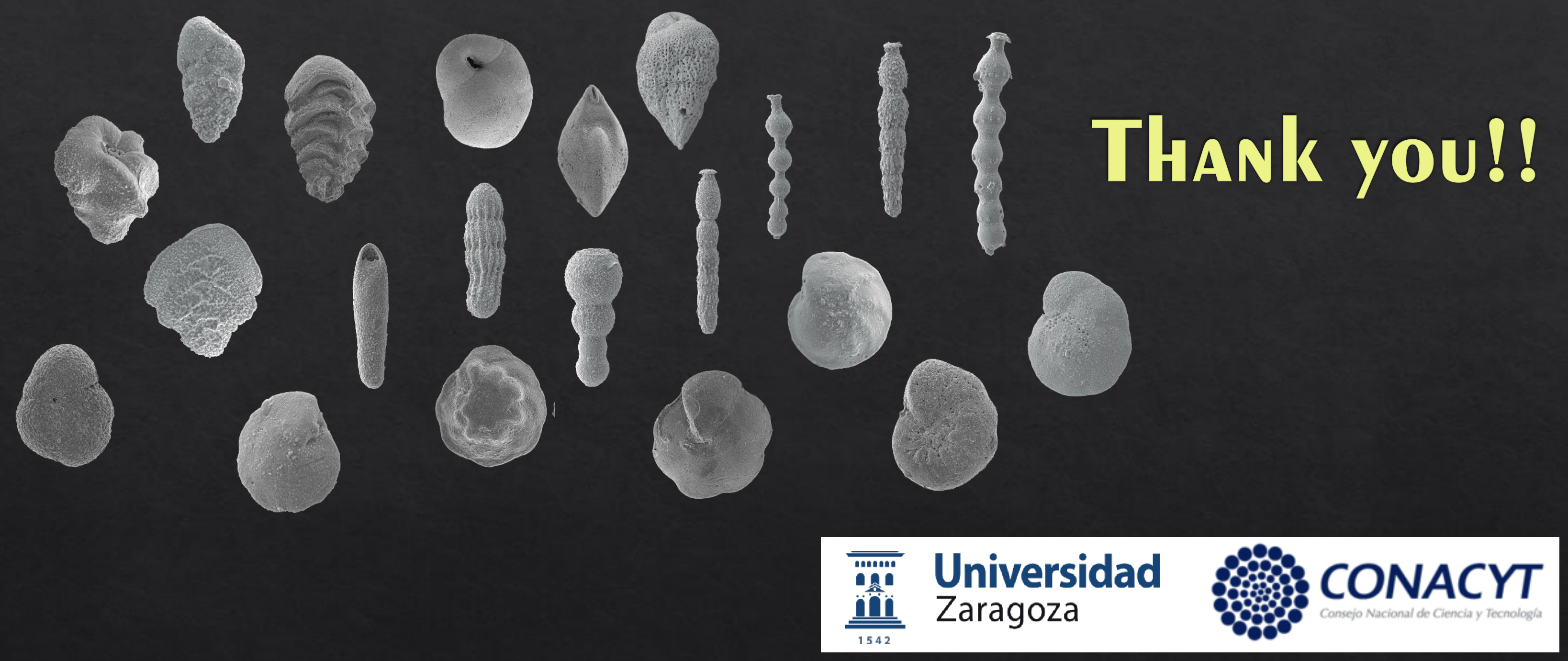

Additional information in:

Arreguín-Rodríguez, G. J., L. Alegret, and E. Thomas (2016), Paleoceanography, 31, doi:10.1002/2015PA002837. 